Article

\title{
Organ-Specific Analysis of Morus alba Using a Gel-Free/Label-Free Proteomic Technique
}

\author{
Wei Zhu ${ }^{1,+}{ }^{+}$Zhuoheng Zhong ${ }^{1,+}$, Shengzhi Liu ${ }^{1}{ }^{\mathbb{D}}$, Bingxian Yang ${ }^{1}$, Setsuko Komatsu ${ }^{2}$, \\ Zhiwei $\mathrm{Ge}^{3}$ and Jingkui Tian ${ }^{1,4, *(\mathbb{D})}$ \\ 1 College of Biomedical Engineering and Instrument Science, Zhejiang University, Hangzhou 310027, China; \\ rutin@zju.edu.cn (W.Z.); zhongzhh@zju.edu.cn (Z.Z.); bylzs8410@163.com (S.L.); xianyb@zju.edu.cn (B.Y.) \\ 2 Faculty of Environmental and Information Sciences, Fukui University of Technology, Fukui 910-8505, Japan; \\ skomatsu@fukui-ut.ac.jp \\ 3 Analysis Center of Agrobiology and Environmental Sciences, Zhejiang University, Hangzhou 310027, China; \\ gezw@zju.edu.cn \\ 4 Key Laboratory for Biomedical Engineering of Ministry of Education, Zhejiang-Malaysia Joint Research \\ Center for Traditional Medicine, Zhejiang University, Hangzhou 310027, China \\ * Correspondence: tjk@zju.edu.cn; Tel.: +86-571-88273823; Fax: +86-571-87951676 \\ + These authors contributed equally to this work.
}

Received: 15 December 2018; Accepted: 15 January 2019; Published: 16 January 2019

check for updates

\begin{abstract}
Morus alba is an important medicinal plant that is used to treat human diseases. The leaf, branch, and root of Morus can be applied as antidiabetic, antioxidant, and anti-inflammatory medicines, respectively. To explore the molecular mechanisms underlying the various pharmacological functions within different parts of Morus, organ-specific proteomics were performed. Protein profiles of the Morus leaf, branch, and root were determined using a gel-free/label-free proteomic technique. In the Morus leaf, branch, and root, a total of 492, 414, and 355 proteins were identified, respectively, including 84 common proteins. In leaf, the main function was related to protein degradation, photosynthesis, and redox ascorbate/glutathione metabolism. In branch, the main function was related to protein synthesis/degradation, stress, and redox ascorbate/glutathione metabolism. In root, the main function was related to protein synthesis/degradation, stress, and cell wall. Additionally, organ-specific metabolites and antioxidant activities were analyzed. These results revealed that flavonoids were highly accumulated in Morus root compared with the branch and leaf. Accordingly, two root-specific proteins named chalcone flavanone isomerase and flavonoid 3,5-hydroxylase were accumulated in the flavonoid pathway. Consistent with this finding, the content of the total flavonoids was higher in root compared to those detected in branch and leaf. These results suggest that the flavonoids in Morus root might be responsible for its biological activity and the root is the main part for flavonoid biosynthesis in Morus.
\end{abstract}

Keywords: Morus; organ; gel-free/label-free proteomics; flavonoid; antioxidant activity

\section{Introduction}

Mulberry tree (Morus alba L.) is a deciduous woody shrub in the family Moraceae and widely cultivated in China, Korea, India, and Japan [1]. In addition to its use in sericulture, Morus can be used in fruit production, tolerating saline soils, and soil retention in loess soils [2,3]. In China, different parts of the mulberry tree have a long history of being used in traditional Chinese medicine to treat human diseases such as diabetes, arthritis, and rheumatism [4]. Therefore, Morus has attracted attention for its pharmaceutical value. For example, the mulberry leaf has been proven to modulate the cardiovascular system through endothelial nitric oxide synthase signaling [5] and mulberry-leaf polysaccharides, 
which are one of the main active components in mulberry leaf, have been purified from an ethanol extraction and showed potential antioxidative activities [6]. The mulberry-branch bark had a powerful antidiabetic effect that could rescue gluconeogenesis and glycogen synthesis by protecting genes in the phosphatidylinositol-3 kinase and protein kinase B signaling pathways [7]. Furthermore, the ethanol extraction of mulberry root bark could effectively ameliorate hyperlipidemia and four major active compounds, including mulberrofuran $\mathrm{C}$, sanggenon $\mathrm{G}$, moracin $\mathrm{O}$, and moracin $\mathrm{P}$, were isolated [8]. However, the mechanisms for the different biological activity in different parts of Morus remain unclear.

For most medicinal plants, their pharmaceutical value varies in different parts of the plant. For example, the Scutellaria baicalensis root rather than its aerial parts can be used as a traditional Chinese medicine for its anticancer, anti-HIV, and antibacterial effects [9]. The flower from Coreopsis tinctorial has been reported to possess antioxidative and antidiabetic activities and is used as a health food, while its stems and leaves are commonly discarded [10]. Organ- and tissue-specific studies are an effective way to discover the reason for these phenomena and aid in the quality control and pharmacological evaluation of medicinal plants, especially for medicinal plants such as Morus whose vegetative organs (root, branch, and leaf) can all be used as medicines. A comparative study on the antioxidant activity and phenolic contents of methanol extractions from mulberry leaf, stem bark, fruit, and root bark indicated that the mulberry stem bark had the highest antioxidant activity [11]. In contrast, the ethanol extraction from mulberry leaf had a higher antioxidant activity than the fruit and stem extractions [12]. Furthermore, the antioxidant activity of the ethanolic extraction from mulberry twigs was better than that from mulberry root bark [13]. However, there have been no systemic studies comparing the antioxidant activities among mulberry root, branch, and leaf, and the mechanisms of their different antioxidant activities are still unknown.

Omics technologies allow for the analysis of the complete set of genomes and are the most popular approaches for performing systemic studies [14]. The majority of functional genomics is based on transcriptomics, proteomics and metabolomics [15]. Proteomic technologies provide one of the best choices for the functional analysis of translated parts of the genome and have been applied in organ-/tissue-specific studies in plants. Zhu et al. [16] performed organ-specific proteomic analysis on the medicinal plant Mahonia and successfully identified the root-specific expressed proteins S-adenosylmethionine synthetase and (S)-tetrahydroprotoberberine. As the roots accumulated the most alkaloids, such as columbamine, jatrorrhizine, palmatine, tetrandrine, and berberine, these proteins are assumed to be involved in alkaloid biosynthesis. Ji et al. [17] conducted a comparative proteomics analysis using healthy and infected leaves from Morus to study the dwarf response mechanism. Therefore, proteomic approaches can provide significantly more detailed protein information in different organs, which may be beneficial for revealing important mechanisms.

Although the leaf, branch, and root of Morus can all be used as traditional Chinese medicine, additional studies are needed to identify the organ-specific factors with medicinal value. In this study, to uncover the molecular mechanisms of the different pharmacological functions in Morus leaf, branch, and root, gel-free/label-free proteomic approach was used. Bioinformatic, phytochemical, and qRT-PCR techniques were used for confirmation of results from proteomics.

\section{Results}

\subsection{The Metabolite Contents and Antioxidant Activity in Morus Root were Higher than in Branch and Leaf}

To reveal differences among the leaf, branch, and root in Morus, five secondary metabolites were identified in the three organs. The leaf, branch and root were collected from mulberry trees and methanol extracts from the three organs were examined by HPLC analysis. From the HPLC chromatograms detected at $320 \mathrm{~nm}, 24,18$, and 40 peaks were observed in the extracts from the leaf, branch, and root, respectively (Figure 1A). Five major secondary metabolites including mulberroside A, oxyresveratrol, kuwanone $\mathrm{H}$, chalcomoracin, and morusin were identified in the root, while only three of the five metabolites (mulberroside A, oxyresveratrol, and morusin) were detected in the branch and 
two of the five metabolites (mulberroside A, and chalcomoracin) were detected in the leaf. Except for oxyresveratrol, the contents of the other four metabolites in the root are more than 10 times higher than those in the leaf and branch (Table 1). To understand the biological differences among the three organs in Morus, the antioxidant activities were evaluated by using an ABTS+ scavenging activity, hydroxyl free radical, and $\mathrm{O}_{2}{ }^{-}$scavenging activity assays. As a result, the root had the strongest ABTS+ scavenging activity, $\mathrm{O}_{2}{ }^{-}$scavenging activity, and hydroxyl free radical inhibition activity, while the leaf had the worst antioxidant activity (Figure 1B).

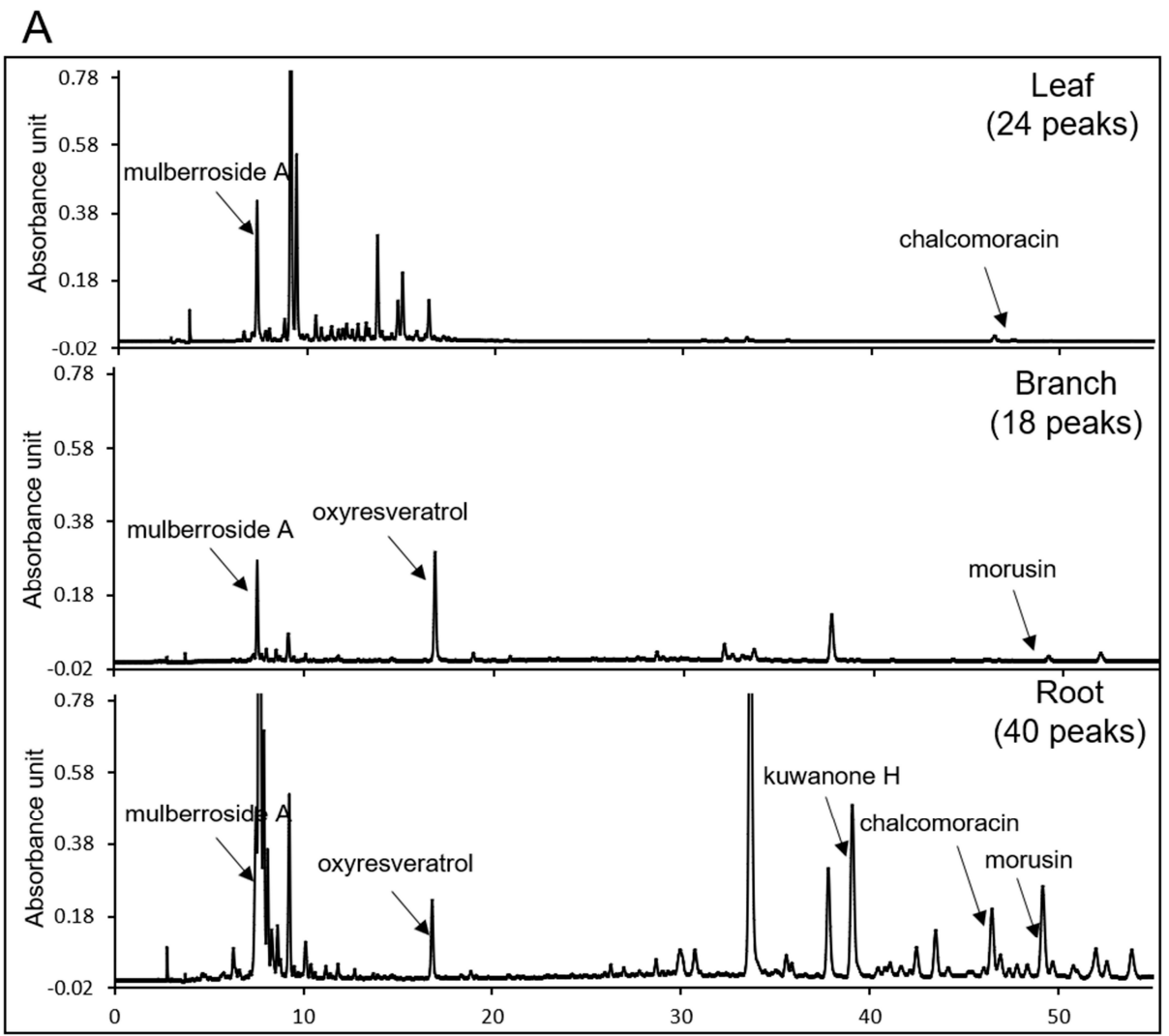

B

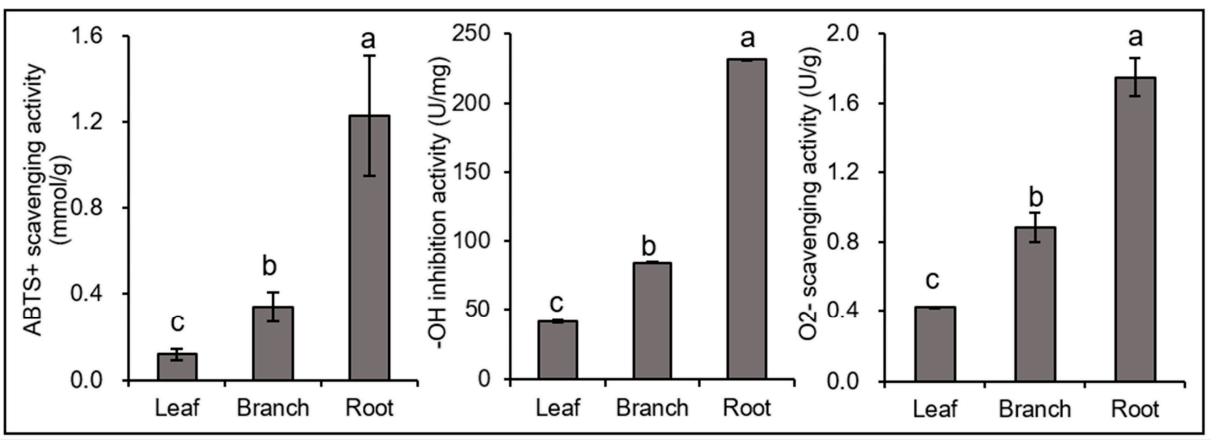

Figure 1. Analysis of the metabolites in Morus leaf, branch, and root and their antioxidant activities. The methanol extracts from Morus leaf, branch, and root were analyzed by HPLC (A). A C18 column was used with a flow rate of $1 \mathrm{~mL} \mathrm{~min}^{-1}$. The peaks were determined at a wavelength of $320 \mathrm{~nm}$. For the determination of the antioxidant activities of Morus leaf, branch, and root, $\mathrm{ABTS}^{+}$scavenging, hydroxyl free radical, and $\mathrm{O}_{2}{ }^{-}$scavenging activities were analyzed (B). The data are shown as the mean $\pm \mathrm{SD}$ from three independent biological replicates. Means with the same letter are not significantly different according to the one-way ANOVA test $(p<0.05)$. 
Table 1. Contents of five secondary metabolites in different organs of Morus.

\begin{tabular}{llllll}
\hline & $\begin{array}{l}\text { Mulberroside A } \\
\text { (mg/g DW) }\end{array}$ & $\begin{array}{l}\text { Oxyresveratrol } \\
\text { (mg/g DW) }\end{array}$ & $\begin{array}{l}\text { Kuwanone H } \\
\text { (mg/g DW) }\end{array}$ & $\begin{array}{l}\text { Chalcomoracin } \\
\text { (mg/g DW) }\end{array}$ & $\begin{array}{l}\text { Morusin } \\
\text { (mg/g DW) }\end{array}$ \\
\hline Leaf & $0.917 \pm 0.015$ & n.d. $*$ & n.d. & $0.045 \pm 0.005$ & n.d. \\
Branch & $0.451 \pm 0.012$ & $0.453 \pm 0.008$ & n.d. & n.d. & $0.043 \pm 0.008$ \\
Root & $24.206 \pm 0.688$ & $0.345 \pm 0.022$ & $5.551 \pm 0.226$ & $0.610 \pm 0.051$ & $2.874 \pm 0.158$ \\
\hline
\end{tabular}

${ }^{*}$ n.d. means the metabolites is not determined in this organ; DW, means dry weight.

\subsection{A Total of 257, 148, and 170 Proteins were Specific to Leaf, Branch, and Root in Morus, Respectively}

To analyze the mechanisms functioning within the three organs, a gel-free proteomics approach was used to identify and determine the abundance of proteins in mulberry leaf, branch, and root with the help of nano LC-MS/MS. A total of 492, 414, and 355 proteins with more than two matched peptides were identified in the leaf (Supplemental Table S1), branch (Supplemental Table S2) and root (Supplemental Table S3), respectively. Among these proteins, 257 (257/492, 52\%), 148 (148/414, 36\%), and $170(170 / 355,48 \%)$ were specific to the leaf, branch, and root, respectively (Figure 2).

To determine the biological processes involved in the three organs, the identified proteins were functionally classified using MapMan bin codes (Figure 2, Supplemental Tables S1-S3, Supplemental Figure S4. In leaf, the main functional categories were related to protein metabolism $(82 / 492,17 \%)$, photosynthesis $(64 / 492,13 \%)$, redox ascorbate/glutathione metabolism $(31 / 492,6 \%)$, stress $(20 / 492$, $4 \%$ ), and tricarboxylic acid cycle (TCA, 17/492, 3\%). In branch, the main functional categories were related to protein metabolism $(67 / 414,16 \%)$, stress $(32 / 414,8 \%)$, photosynthesis $(30 / 414,7 \%)$, redox ascorbate/glutathione metabolism (28/414,7\%), and cell cycle/cell organization and division (17/414, $4 \%)$. In root, the main functional categories were related to protein metabolism $(56 / 355,16 \%)$, stress $(33 / 355,9 \%)$, cell wall $(20 / 355,6 \%)$, RNA metabolism $(19 / 355,5 \%)$, and redox ascorbate/glutathione metabolism $(16 / 355,5 \%)$. Based on these results, proteins related to protein synthesis/degradation comprised the main functional category in all three organs. The abundance of proteins related to redox, TCA cycle, and glycolysis largely differed in the root samples compared to the leaf and branch samples (Figure 2).

\subsection{Functional Characterization of Organ-Specific Proteins Identified from Morus}

To determine the organ-specific protein expression patterns within each organ, leaf-, branch-, and root-specific proteins were functionally categorized and visualized using the MapMan software (version 3.6.0RC1, Aachen, Germany) (Figure 3). In the root, the number of cell wall-related proteins (10 proteins) was larger than in the leaf (four proteins) and branch (two proteins). Moreover, the proteins related to lipid metabolism identified in the root (four proteins) are more than the other organs (one protein for branch and two proteins for leaf). Additionally, five root-specific proteins related to major carbohydrate metabolism are functionally categorized as the degradation of sucrose and starch, while two leaf-specific proteins are involved in the synthesis of sucrose. In amino acid synthesis/metabolism, four root-specific proteins were found to be involved with amino acids; these belonged to the glutamate and aspartate families. There were also four leaf-specific proteins related to amino acid degradation/metabolism. 

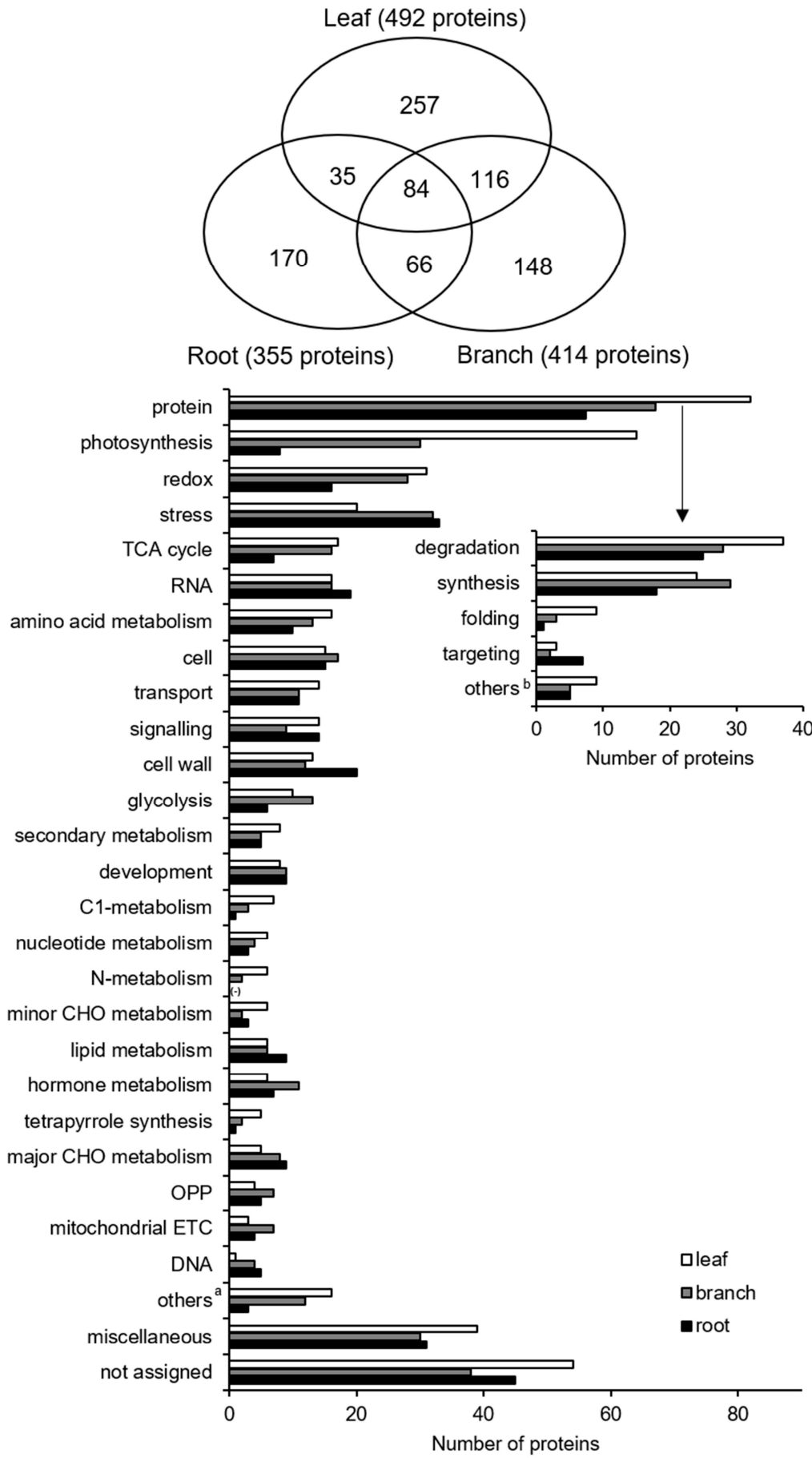

Figure 2. Functional categorization of proteins in leaf, branch, and root from Morus. Leaf (white), branch (gray), and root (black) samples were collected and proteins were extracted, digested, and analyzed by nanoLC-MS/MS. Protein functions were predicted and categorized using MapMan bin codes. Abbreviations: redox, redox ascorbate/glutathione metabolism; TCA, tricarboxylic acid; RNA, RNA processing and regulation of transcription; cell, cell organization, and vesicle transport; $\mathrm{CHO}$, carbohydrates; OPP, oxidative pentose phosphate; ETC, electron transport chains; and DNA, DNA synthesis, and repair. a Others, containing biodegradation of xenobiotics, co-factor and vitamin metabolism, S-assimilation, gluconeogenesis, fermentation, and metal handling. ${ }^{b}$ Others, containing amino acid activation, posttranslational modification, and assembly/cofactor ligation. 


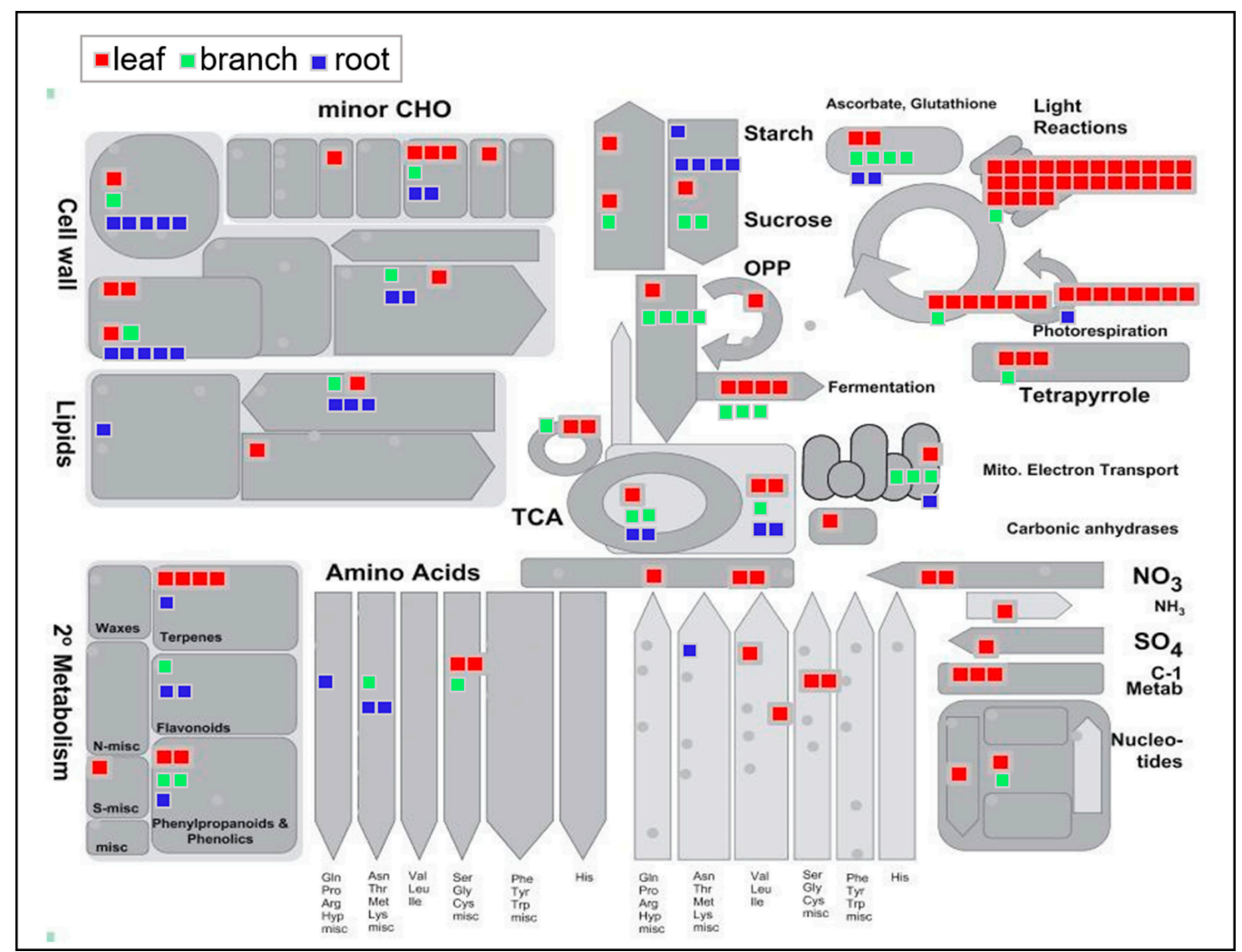

Figure 3. Organ-specific proteins were functionally categorized and visualized using the MapMan software. Leaf- (red), branch- (green), and root-(blue) specific proteins were submitted to the MapMan software (version 3.6.0RC1) using the metabolism overview pathway map. Each square indicates one mapped protein.

There were several specifically identified proteins mapped to secondary metabolism that exhibited organ-specific expression patterns. Therefore, the organ-specific proteins involved in secondary metabolism were visualized using the MapMan software (version 3.6.0RC1, Aachen, Germany) (Supplemental Figure S1). There were eight, five, and four specifically identified proteins from the leaf, branch, and root samples, respectively. Leaf-specific proteins related to secondary metabolism mainly accumulated in the non-MVA and phenlypropanoid pathways. Branch-specific proteins related to secondary metabolism mainly accumulated in the phenlypropanoid and lignin/lignan pathways. Notably, the root-specific proteins related to secondary metabolism, such as chalcone flavanone isomerase and flavonoid 3,5-hydroxylase, were accumulated in the flavonoid pathway, especially for the biosynthesis of chalcones and dihydroflavonols (Figure 4).

\subsection{Largely Differential Common Proteins Were Identified among Three Organs in Morus}

To further analyze the differences in the proteins among the three organs, Venn diagram analysis was performed on the proteins identified in the three organs (Figure 2). A total of 84 proteins was commonly identified from the three organs, and the abundance of peroxidase (protein number 2) in the root was significantly higher than in the branch and leaf (Table 2). The abundance of proteasome (protein number 9) in the root was approximately six times higher than that found in the leaf. However, isoflavone reductase homolog P3 (protein number 48), which is the only protein involved in secondary metabolism from the commonly identified protein group, was the most abundant in the branch samples $(1.17 \mathrm{~mol} \%)$ compared to the leaf $(0.33 \mathrm{~mol} \%)$ and root $(0.37 \mathrm{~mol} \%)$ samples. Furthermore, the abundance of triosephosphate isomerase in the leaf is approximately ten times higher than in the root. 


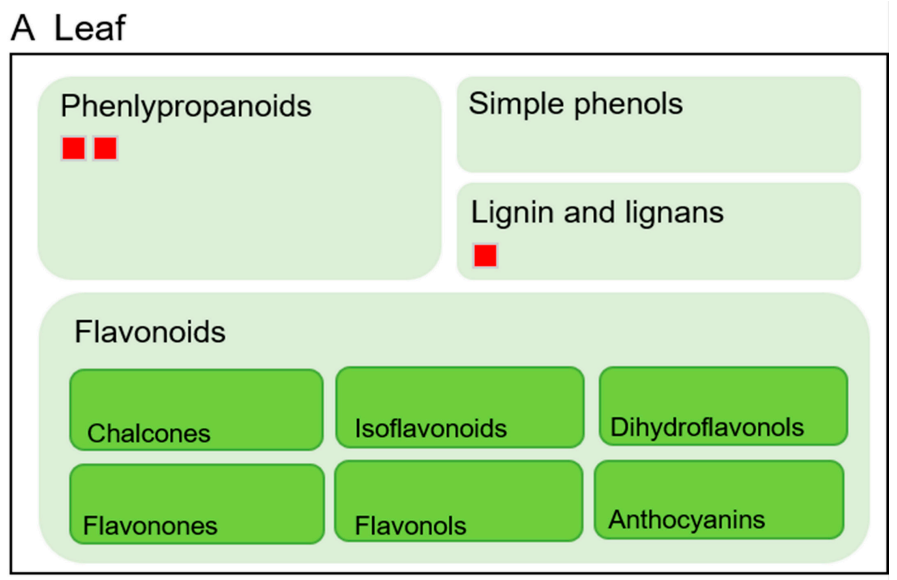

\section{B Branch}

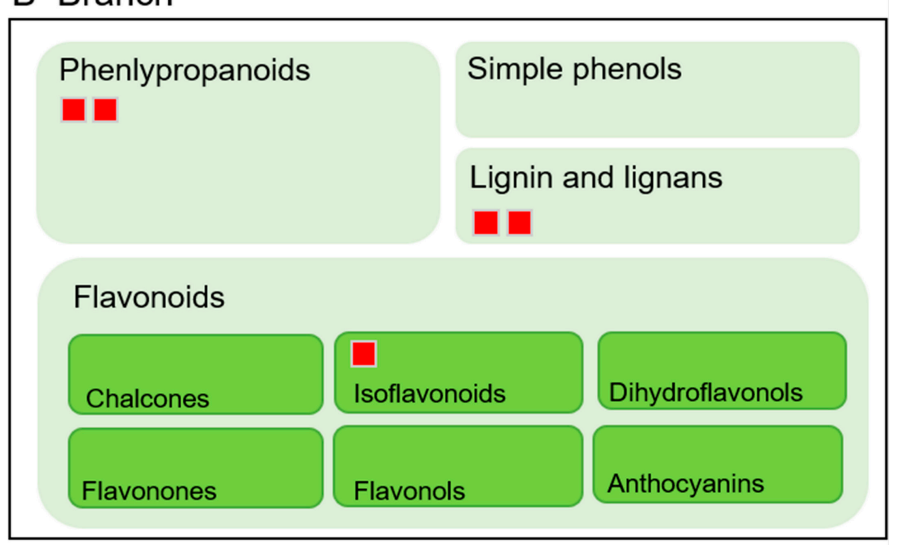

\section{Root}

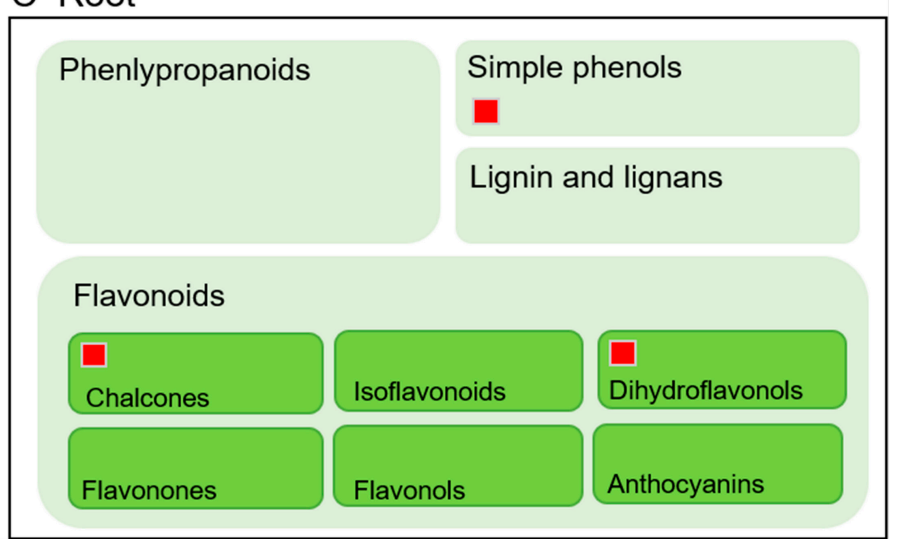

Figure 4. Comparison of the organ-specific proteins related to the flavonoid, phenlypropanoid, simple phenol, and lignin. Leaf- (A), branch- (B), and root- (C) specific proteins related to secondary metabolism were submitted to the MapMan software (version 3.6.0RC1). Each red square indicates one mapped protein. 
Table 2. Common proteins identified in the leaf, branch, and root of Morus by gel-free/label-free proteomic analysis

\begin{tabular}{|c|c|c|c|c|c|c|c|c|c|}
\hline \multirow{2}{*}{ No. } & \multirow{2}{*}{ Protein ID $^{a}$} & \multirow{2}{*}{ Description } & \multirow{2}{*}{ M.P. ${ }^{b}$} & \multirow{2}{*}{ Score } & \multirow{2}{*}{ Mass (Da) } & \multirow{2}{*}{ Function $^{c}$} & \multicolumn{3}{|c|}{$\operatorname{Mol}(\%)^{d}$} \\
\hline & & & & & & & leaf & stem & root \\
\hline 1 & Morus009492.p1 & Macrophage migration inhibitory factor homolog & 8 & 203 & 8961 & not assigned & 3.10 & 2.43 & 3.69 \\
\hline 2 & Morus001961.p1 & Peroxidase 12 & 16 & 244 & 38,426 & misc & 0.57 & 1.29 & 3.62 \\
\hline 3 & Morus018316.p1 & Superoxide dismutase 1 copper chaperone & 9 & 339 & 11,171 & metal handling & 2.11 & 1.69 & 2.48 \\
\hline 4 & Morus009000.p1 & $60 \mathrm{~S}$ acidic ribosomal protein $\mathrm{P} 2 \mathrm{~B}$ & 12 & 110 & 11,673 & protein & 1.62 & 2.32 & 2.32 \\
\hline 5 & Morus023628.p1 & Tubulin beta- 1 chain & 22 & 578 & 51,015 & cell & 1.11 & 1.83 & 1.99 \\
\hline 6 & Morus017847.p1 & Ribonuclease UK114 & 16 & 266 & 19,960 & RNA & 1.08 & 0.27 & 1.80 \\
\hline 7 & Morus017207.p1 & Proteasome subunit alpha type- 4 & 6 & 173 & 27,440 & protein & 0.24 & 0.34 & 1.58 \\
\hline 8 & Morus003952.p1 & Lipoxygenase homology domain-containing protein 1 & 6 & 154 & 21,171 & not assigned & 0.50 & 0.95 & 1.44 \\
\hline 9 & Morus022430.p1 & Proteasome subunit beta type-1 & 11 & 313 & 24,861 & protein & 0.68 & 0.56 & 1.44 \\
\hline 10 & Morus022592.p1 & Thaumatin-like protein 1a & 18 & 362 & 26,984 & stress & 1.02 & 0.44 & 1.41 \\
\hline 11 & Morus022525.p1 & Calmodulin & 9 & 250 & 16,894 & signaling & 1.03 & 1.12 & 1.31 \\
\hline 12 & Morus015082.p1 & Auxin-repressed $12.5 \mathrm{kDa}$ protein & 3 & 89 & 13,355 & development & 0.49 & 1.99 & 1.30 \\
\hline 13 & Morus003616.p1 & Fructokinase-2 & 10 & 137 & 35,370 & major $\mathrm{CHO}$ metabolism & 0.42 & 0.79 & 1.25 \\
\hline 14 & Morus017382.p1 & Calcium-binding protein CML27 & 4 & 116 & 18,705 & signaling & 0.26 & 0.29 & 1.05 \\
\hline 15 & Morus008669.p1 & Allene oxide cyclase 2 , chloroplastic & 6 & 168 & 27,569 & hormone metabolism & 0.60 & 1.24 & 0.99 \\
\hline 16 & Morus010743.p1 & Triosephosphate isomerase, cytosolic & 19 & 263 & 27,548 & glycolysis & 1.27 & 1.66 & 0.99 \\
\hline 17 & Morus004210.p1 & Glucan endo-1,3-beta-glucosidase, basic vacuolar isoform & 20 & 178 & 39,002 & misc & 0.63 & 0.34 & 0.94 \\
\hline 18 & Morus011779.p1 & Superoxide dismutase [Cu-Zn], chloroplastic & 22 & 579 & 29,603 & redox & 0.74 & 0.31 & 0.90 \\
\hline 19 & Morus001936.p1 & Peroxiredoxin-2B & 17 & 350 & 17,391 & redox & 1.22 & 1.48 & 0.90 \\
\hline 20 & Morus004201.p1 & Universal stress protein A-like protein & 9 & 223 & 18,591 & stress & 0.58 & 0.58 & 0.82 \\
\hline 21 & Morus001634.p1 & Nucleoside diphosphate kinase 1 & 11 & 215 & 16,322 & nucleotide metabolism & 1.35 & 0.78 & 0.78 \\
\hline 22 & Morus003013.p1 & Phosphoglycerate kinase, cytosolic & 59 & 1143 & 42,729 & glycolysis & 1.72 & 2.17 & 0.75 \\
\hline 23 & Morus028068.p1 & Polygalacturonase inhibitor 1 & 10 & 306 & 37,677 & cell wall & 0.86 & 0.73 & 0.73 \\
\hline 24 & Morus013807.p1 & Fructose-bisphosphate aldolase, cytoplasmic isozyme & 23 & 584 & 38,459 & glycolysis & 0.92 & 1.82 & 0.71 \\
\hline 25 & Morus020532.p1 & Glutaredoxin & 5 & 244 & 15,307 & redox & 0.75 & 0.69 & 0.69 \\
\hline 26 & Morus023908.p1 & Uncharacterized protein & 15 & 271 & 57,888 & protein & 0.50 & 1.55 & 0.69 \\
\hline 27 & Morus018475.p1 & Peroxidase 54 & 5 & 128 & 36,921 & misc & 0.13 & 0.47 & 0.67 \\
\hline 28 & Morus025517.p1 & Tubulin alpha chain & 18 & 426 & 49,920 & cell & 0.68 & 0.72 & 0.66 \\
\hline 29 & Morus002489.p1 & Nascent polypeptide-associated complex subunit alpha-like protein 1 & 11 & 285 & 22,279 & protein & 1.01 & 0.34 & 0.65 \\
\hline 30 & Morus014304.p1 & Plastocyanin, chloroplastic & 23 & 661 & 16,620 & photosynthesis & 1.16 & 0.62 & 0.62 \\
\hline 31 & Morus024265.p1 & Aquaporin PIP1-3 & 5 & 67 & 30,856 & transport & 0.22 & 0.37 & 0.59 \\
\hline 32 & Morus008884.p1 & Cysteine proteinase RD21a & 10 & 350 & 52,217 & protein & 0.35 & 0.32 & 0.58 \\
\hline 33 & Morus025862.p1 & ATP synthase subunit beta, mitochondrial & 33 & 1017 & 59,400 & mitochondrial electron transport & 1.06 & 1.43 & 0.54 \\
\hline 34 & Morus026982.p1 & Allene oxide synthase, chloroplastic & 11 & 164 & 56,861 & hormone metabolism & 0.30 & 0.91 & 0.54 \\
\hline 35 & Morus007342.p1 & Peroxiredoxin-2F, mitochondrial & 12 & 178 & 22,580 & redox & 0.77 & 1.03 & 0.52 \\
\hline 36 & Morus009738.p1 & ATP-dependent Clp protease proteolytic subunit 5 , chloroplastic & 4 & 146 & 34,203 & protein & 0.13 & 0.21 & 0.52 \\
\hline 37 & Morus009210.p1 & $60 \mathrm{~S}$ acidic ribosomal protein $\mathrm{P} 3-2$ & 2 & 71 & 12,022 & protein & 0.42 & 0.48 & 0.48 \\
\hline
\end{tabular}


Table 2. Cont.

\begin{tabular}{|c|c|c|c|c|c|c|c|c|c|}
\hline \multirow{2}{*}{ No. } & \multirow{2}{*}{ Protein ID ${ }^{\text {a }}$} & \multirow{2}{*}{ Description } & \multirow{2}{*}{ M.P. ${ }^{b}$} & \multirow{2}{*}{ Score } & \multirow{2}{*}{ Mass (Da) } & \multirow{2}{*}{ Function $^{c}$} & \multicolumn{3}{|c|}{ Mol (\%) ${ }^{d}$} \\
\hline & & & & & & & leaf & stem & root \\
\hline 38 & Morus007901.p1 & Actin-7 & 30 & 717 & 41,897 & cell & 1.02 & 1.20 & 0.47 \\
\hline 39 & Morus007352.p1 & Stem-specific protein TSJT1 & 7 & 96 & 25,521 & metal handling & 0.18 & 0.45 & 0.45 \\
\hline 40 & Morus026327.p1 & Heat shock cognate $70 \mathrm{kDa}$ protein 1 & 41 & 791 & 71,553 & stress & 0.91 & 0.67 & 0.44 \\
\hline 41 & Morus021433.p1 & Malate dehydrogenase, cytoplasmic & 20 & 463 & 35,912 & TCA & 0.57 & 0.95 & 0.43 \\
\hline 42 & Morus006184.p1 & Cysteine synthase & 33 & 572 & 34,400 & amino acid metabolism & 1.77 & 0.59 & 0.39 \\
\hline 43 & Morus018842.p1 & 2-Cys peroxiredoxin BAS1-like, chloroplastic & 23 & 321 & 29,121 & redox & 0.81 & 0.65 & 0.39 \\
\hline 44 & Morus022454.p1 & Fasciclin-like arabinogalactan protein 8 & 6 & 120 & 43,455 & cell wall & 0.22 & 0.16 & 0.39 \\
\hline 45 & Morus008883.p1 & Uncharacterized protein & 6 & 104 & 49,487 & signaling & 0.17 & 0.34 & 0.38 \\
\hline 46 & Morus000210.p1 & Calvin cycle protein $\mathrm{CP} 12$ & 8 & 288 & 14,542 & photosynthesis & 0.34 & 0.38 & 0.38 \\
\hline 47 & Morus002920.p1 & Thioredoxin M-type 4, chloroplastic & 6 & 164 & 20,233 & redox & 0.42 & 0.26 & 0.37 \\
\hline 48 & Morus018564.p1 & Isoflavone reductase homolog $\mathrm{P} 3$ & 12 & 102 & 45,171 & secondary metabolism & 0.33 & 1.17 & 0.37 \\
\hline 49 & Morus013051.p1 & Adenosine kinase 2 & 7 & 216 & 37,797 & nucleotide metabolism & 0.65 & 0.41 & 0.35 \\
\hline 50 & Morus000836.p1 & Ribulose bisphosphate carboxylase large chain (Fragment) & 290 & 4805 & 61,599 & photosynthesis & 1.18 & 0.63 & 0.33 \\
\hline 51 & Morus015202.p1 & Uncharacterized protein & 11 & 234 & 33,994 & not assigned & 0.46 & 0.39 & 0.32 \\
\hline 52 & Morus014140.p1 & Plastid-lipid-associated protein, chloroplastic & 10 & 281 & 35,137 & cell & 0.52 & 0.31 & 0.31 \\
\hline 53 & Morus025784.p1 & Phospholipase D alpha 1 & 4 & 47 & 92,059 & lipid metabolism & 0.05 & 0.37 & 0.30 \\
\hline 54 & Morus018550.p1 & Glycine-rich RNA-binding protein GRP1A & 5 & 165 & 18,416 & RNA & 0.39 & 0.29 & 0.29 \\
\hline 55 & Morus014011.p1 & Glycerophosphoryl diester phosphodiesterase 2 & 6 & 295 & 81,816 & lipid metabolism & 0.16 & 0.12 & 0.29 \\
\hline 56 & Morus019087.p1 & Putative mitochondrial 2-oxoglutarate/malate carrier protein & 12 & 194 & 32,224 & transport & 0.98 & 0.29 & 0.28 \\
\hline 57 & Morus002874.p1 & Leucine aminopeptidase 3 , chloroplastic & 39 & 981 & 60,563 & protein & 0.96 & 1.09 & 0.27 \\
\hline 58 & Morus010230.p1 & Superoxide dismutase $[\mathrm{Cu}-\mathrm{Zn}]$ & 2 & 63 & 20,420 & redox & 0.34 & 0.37 & 0.26 \\
\hline 59 & Morus019413.p1 & Cysteine proteinase $15 \mathrm{~A}$ & 9 & 259 & 41,574 & protein & 0.23 & 0.12 & 0.26 \\
\hline 60 & Morus015818.p1 & Probable glucan endo-1,3-beta-glucosidase A6 & 3 & 111 & 52,145 & misc & 0.15 & 0.17 & 0.24 \\
\hline 61 & Morus020384.p1 & Cysteine synthase, chloroplastic/chromoplastic & 21 & 258 & 43,997 & amino acid metabolism & 0.52 & 0.11 & 0.24 \\
\hline 62 & Morus013361.p1 & Protein disulfide-isomerase & 15 & 432 & 56,492 & redox & 0.66 & 0.92 & 0.22 \\
\hline 63 & Morus007114.p1 & Glycine-rich RNA-binding protein 2 & 3 & 170 & 27,802 & RNA & 0.17 & 0.19 & 0.19 \\
\hline 64 & Morus011198.p1 & L-ascorbate peroxidase, cytosolic & 26 & 392 & 27,414 & redox & 1.05 & 1.13 & 0.19 \\
\hline 65 & Morus008123.p1 & IAA-amino acid hydrolase ILR1-like 5 & 5 & 89 & 47,707 & hormone metabolism & 0.15 & 0.50 & 0.18 \\
\hline 66 & Morus024851.p1 & Catalase isozyme 1 & 19 & 137 & 57,208 & redox & 0.62 & 0.32 & 0.18 \\
\hline 67 & Morus017351.p1 & Serine carboxypeptidase-like 50 & 5 & 55 & 49,604 & protein & 0.15 & 0.14 & 0.17 \\
\hline 68 & Morus014667.p1 & Alpha-xylosidase & 15 & 257 & 103,539 & misc & 0.17 & 0.45 & 0.15 \\
\hline 69 & Morus017174.p1 & Predicted protein & 8 & 193 & 33,060 & signaling & 0.20 & 0.27 & 0.15 \\
\hline 70 & Morus024951.p1 & Triosephosphate isomerase, chloroplastic & 42 & 655 & 34,813 & photosynthesis & 1.66 & 0.99 & 0.15 \\
\hline 71 & Morus008661.p1 & 14-3-3-like protein A & 15 & 283 & 81,889 & cell & 0.26 & 0.37 & 0.14 \\
\hline 72 & Morus016271.p1 & Elongation factor 2 & 14 & 106 & 99,403 & protein & 0.11 & 0.44 & 0.14 \\
\hline 73 & Morus001657.p1 & 6-phosphogluconolactonase 4 , chloroplastic & 6 & 108 & 35,151 & OPP & 0.18 & 0.97 & 0.14 \\
\hline 74 & Morus009365.p1 & $\begin{array}{l}\text { 5-methyltetrahydropteroyltriglutamate-homocysteine } \\
\text { methyltransferase }\end{array}$ & 13 & 188 & 84,904 & amino acid metabolism & 0.17 & 0.46 & 0.14 \\
\hline
\end{tabular}


Table 2. Cont.

\begin{tabular}{|c|c|c|c|c|c|c|c|c|c|}
\hline \multirow{2}{*}{ No. } & \multirow{2}{*}{ Protein ID ${ }^{a}$} & \multirow{2}{*}{ Description } & \multirow{2}{*}{ M.P. ${ }^{b}$} & \multirow{2}{*}{ Score } & \multirow{2}{*}{ Mass (Da) } & \multirow{2}{*}{ Function $^{c}$} & \multicolumn{3}{|c|}{$\operatorname{Mol}(\%)^{d}$} \\
\hline & & & & & & & leaf & stem & root \\
\hline 75 & Morus007784.p1 & UTP-glucose-1-phosphate uridylyltransferase & 26 & 372 & 76,133 & glycolysis & 0.48 & 0.80 & 0.13 \\
\hline 76 & Morus017695.p1 & $31 \mathrm{kDa}$ ribonucleoprotein, chloroplastic & 10 & 230 & 38,128 & RNA & 0.17 & 0.13 & 0.13 \\
\hline 77 & Morus007494.p1 & RuBisCO large subunit-binding protein subunit alpha, chloroplastic & 30 & 964 & 62,000 & photosynthesis & 1.29 & 0.33 & 0.11 \\
\hline 78 & Morus011664.p1 & L-ascorbate oxidase homolog & 4 & 53 & 60,522 & not assigned & 0.13 & 0.37 & 0.11 \\
\hline 79 & Morus006060.p1 & V-type proton ATPase subunit B2 & 10 & 400 & 63,333 & transport & 0.41 & 0.16 & 0.11 \\
\hline 80 & Morus004111.p1 & Calreticulin & 7 & 266 & 50,196 & signaling & 0.32 & 0.56 & 0.10 \\
\hline 81 & Morus013778.p1 & Monodehydroascorbate reductase & 13 & 142 & 49,982 & redox & 0.30 & 0.33 & 0.10 \\
\hline 82 & Morus024141.p1 & Beta-D-xylosidase 4 & 6 & 187 & 84,604 & cell wall & 0.14 & 0.10 & 0.10 \\
\hline 83 & Morus007961.p1 & Hypothetical protein & 7 & 62 & 95,561 & not assigned & 0.05 & 0.07 & 0.09 \\
\hline 84 & Morus025925.p1 & Alpha-glucosidase & 6 & 207 & 93,365 & misc & 0.12 & 0.25 & 0.07 \\
\hline
\end{tabular}

a Protein ID, according to the Morus database; ${ }^{\mathrm{b}}$ M.P., number of matched peptides; ${ }^{\mathrm{c}}$ Function, function categorized using MapMan bin codes; ${ }^{\mathrm{d}}$ Mol (\%), protein abundance; misc, miscellaneous; protein, protein synthesis/degradation/folding/targeting; cell, cell organization/vesicle transport; RNA, RNA processing/regulation of transcription; redox, redox ascorbate/glutathione metabolism; TCA, tricarboxylic acid cycle; and OPP, oxidative pentose phosphate. 


\subsection{TCA Cycle and Glycolysis Pathways Largely Differed among the Three Organs}

To better understand the different metabolic pathways that are active in the leaf, branch, and root of Morus, the identified proteins from each organ were mapped to the TCA cycle and glycolysis pathways using the KEGG database (Figures 5 and 6). In the TCA cycle, the abundance of dihydrolipoyl dehydrogenase (EC1.8.1.4) in the leaves was higher than that in the branches, and no dihydrolipoyl dehydrogenase was detected in the roots. The abundance of NADP-dependent malic enzyme (EC1.1.1.40) in the branches was higher than in the leaves and roots. The abundance of malate dehydrogenase (EC1.1.1.37) in the leaves was nearly three times greater than that in the roots. The abundance fumarate hydratase (EC4.2.1.2) in the leaves was more than three times higher than that in the branches. Furthermore, isocitrate dehydrogenase (EC1.1.1.42) was only identified in the branches (Figure 5). In the glycolysis pathway, the abundance of fructose bisphosphate aldolase (EC4.1.2.13), phosphoglycerate kinase (EC2.7.2.3), and enolase (EC4.2.1.11) in the roots were higher than in the branches and roots. Additionally, pyruvate kinase (EC2.7.1.40) was only identified in the branches (Figure 6).
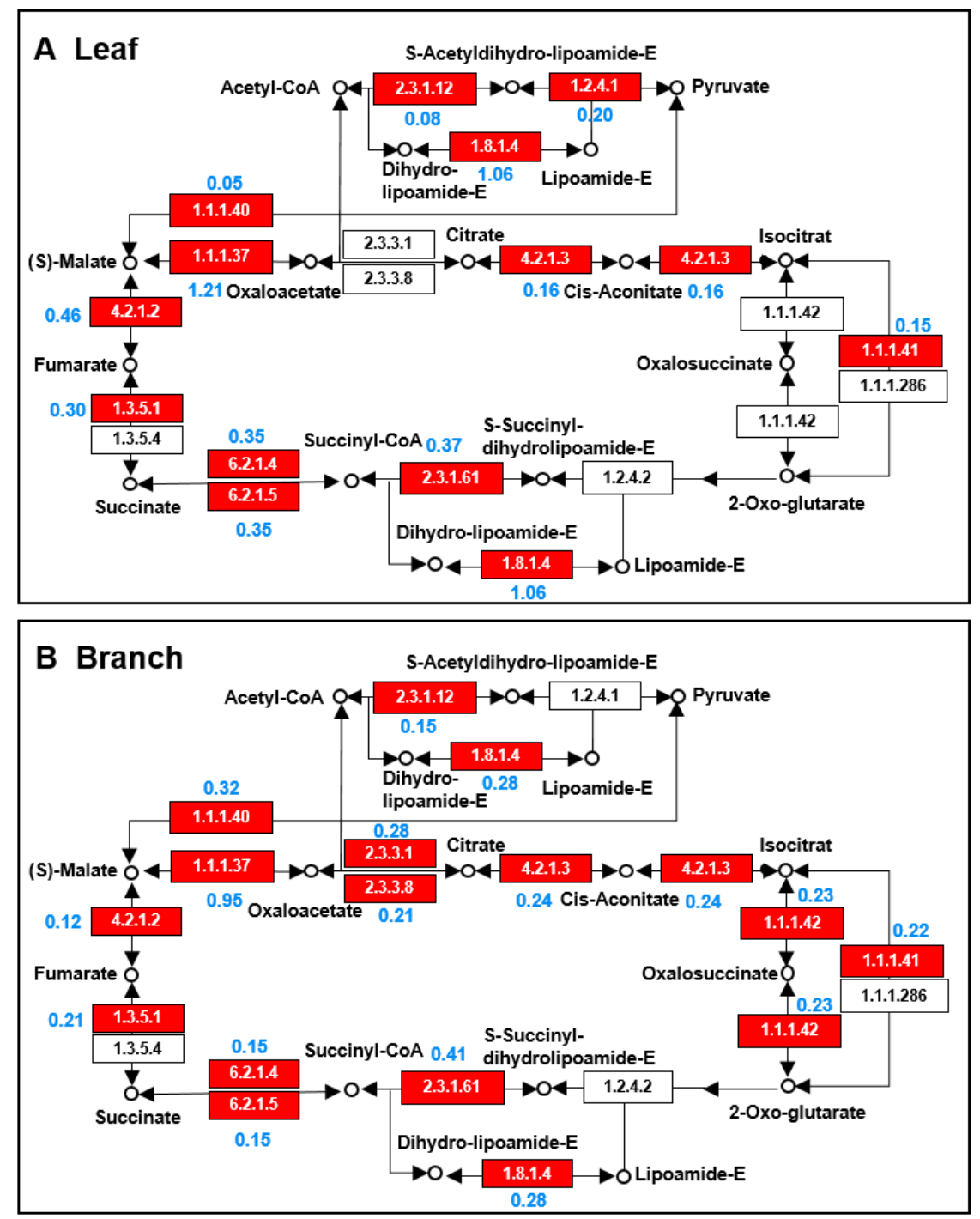

Figure 5. Cont. 


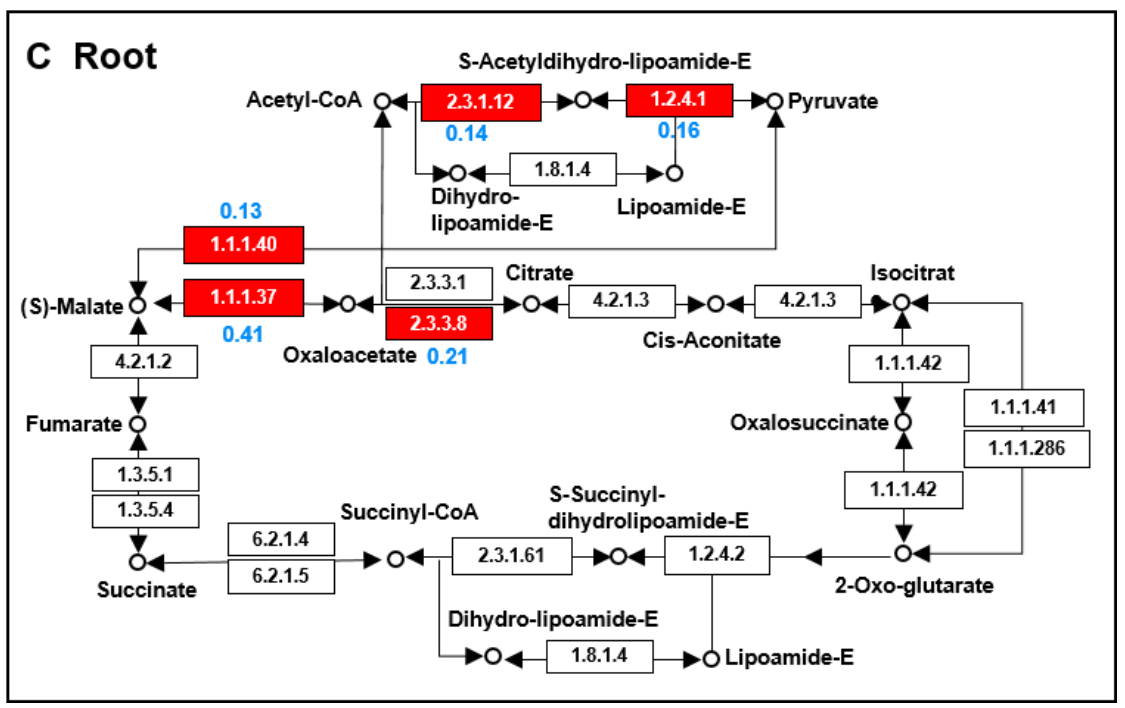

Figure 5. Mapping of proteins related to the TCA cycle in three organs from Morus. The TCA cycle pathways were identified by the mapping of the identified proteins from the leaf (A), branch (B), and root $(\mathbf{C})$ using the KEGG database. Enzymes in red represent identified proteins, and the blue number represents the protein abundance. The EC number for the following proteins are 1.1.1.37, malate dehydrogenase; 1.1.1.40, malate dehydrogenase (oxaloacetate-decarboxylating) (NADP+); 1.1.1.41, isocitrate dehydrogenase (NAD+); 1.1.1.42, isocitrate dehydrogenase; 1.1.1.286, homoisocitrate dehydrogenase; 1.2.4.1, pyruvate dehydrogenase E1; 1.2.4.2, 2-oxoglutarate dehydrogenase; 1.3.5.1, succinate dehydrogenase; 1.3.5.4, fumarate reductase; 1.8.1.4, dihydrolipoamide dehydrogenase; 2.3.3.1, citrate synthase; 2.3.3.8, ATP-citrate synthase; 2.3.1.12, pyruvate dehydrogenase; 2.3.1.61, dihydrolipoamide succinyltransferase; 4.2.1.2, fumarate hydratase; 4.2.1.3, aconitate hydratase; 6.2.1.4, succinyl-CoA synthetase; and 6.2.1.5, ATP-citrate synthase.

\subsection{Total Flavonoid Contents were the Highest in the Roots}

The proteomics analysis of Morus revealed that two proteins involved in the flavonoid biosynthetic pathway were only identified in the roots (Figure 4). Based on this finding, the total flavonoid contents of the three organs in Morus were analyzed to confirm whether the flavonoids accumulated in the roots. The total flavonoids extracted from the leaves, branches, and roots of Morus were analyzed using a colorimetric method. The results confirmed that the total flavonoid contents in the roots were significantly higher than in the leaves and branches (Figure 7A); the levels were approximately 1.5 times higher than in the leaves and four times higher than in the branches (Supplemental Table S4).

\subsection{Expression of Genes Related to Root- and Branch-Specific Proteins}

Functional characterization of the root-specific proteins showed that chalcone flavanone isomerase, which is involved in secondary metabolism, was accumulated through the flavonoid pathway (Figure 4). The abundance of isoflavone reductase in the branch was higher than in the leaf and root (Table 2). Moreover, the abundance of phosphoglycerate kinase in the branch, which is involved in the glycolysis pathway, was higher than in the other organs (Figure 6). Based on this finding, these three genes, chalcone flavanone isomerase (CHI), isoflavone reductase (ISO), and phosphoglycerate kinase (PGK), were selected for further analysis of their mRNA expression levels (Figure 7B). Among the examined genes, the mRNA expression of $\mathrm{CHI}$ in the root is significantly higher than in the leaf and branch. Additionally, the expression of PGK and ISO in the branch is significantly higher than in the root (Figure 7B). 

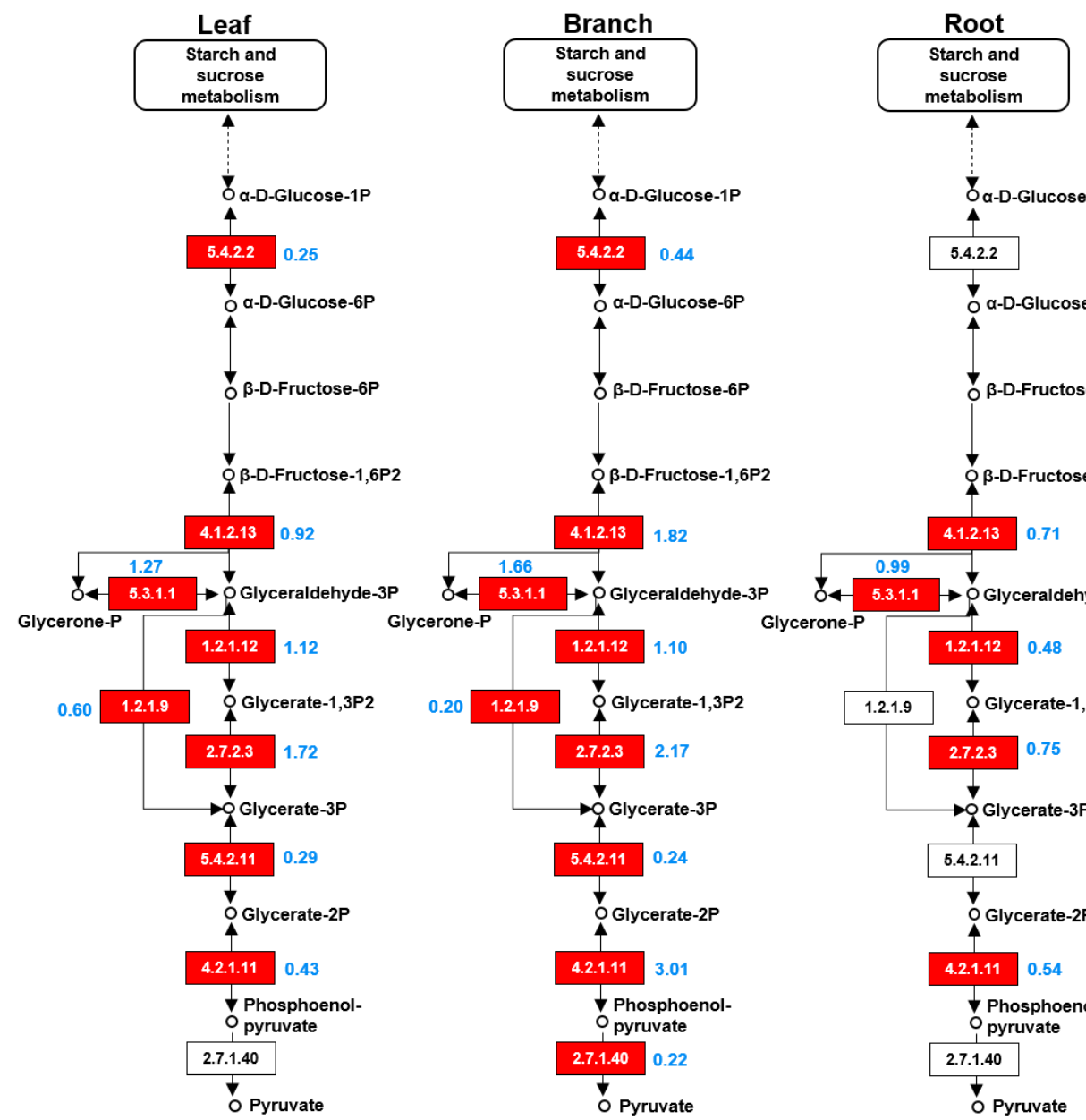

Starch and

metabolism

4

5.4.2.2 0.25

a-D-Glucose-6P

$\beta$-D-Fructose-6P

${ }^{\beta}$-D-Fructose-1,6P2

4.1.2.13 0.92

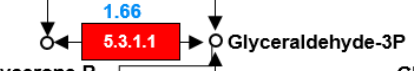

Glycerone-P
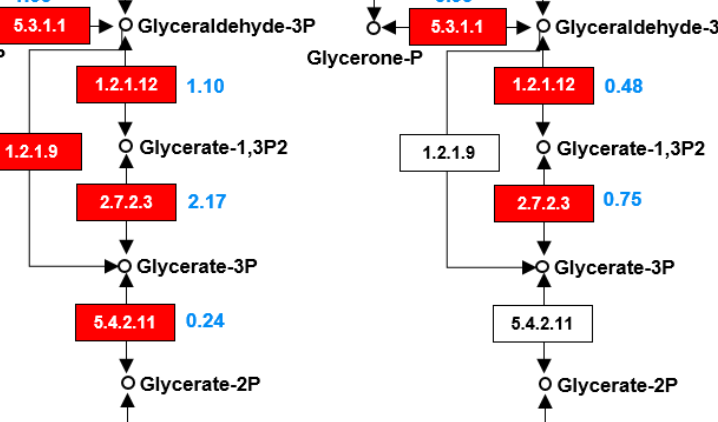

1.2.1.9

Glycerate-1,3P2

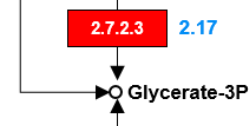

\begin{tabular}{|l|l}
\hline 5.4.2.11 0.24 &
\end{tabular}

OGlycerate-2P

Oेa-D-Glucose-1P

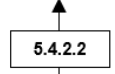

$\alpha$-D-Glucose-6P

수

$\beta$-D-Fructose-6P

$\beta$-D-Fructose-1,6P2

4.1.2.13 0.71

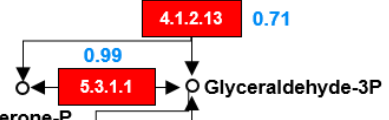

4.2.1.11 3.0

4.2.1.11 0.54

$\checkmark$ Phosphoenol-

$\checkmark$ Phosphoenol-

pyruvate

\begin{tabular}{|l|l} 
2.7.1.40 & 0.22 \\
\hline
\end{tabular}

O Pyruvate

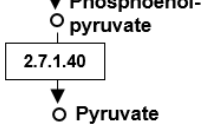

Figure 6. Mapping of proteins related to glycolysis in the three organs from Morus. The glycolysis pathways were identified by the mapping of the identified proteins from the leaf (A), branch (B), and root (C) using the KEGG database. Enzymes in red represent identified proteins, and the blue number represents the protein abundance. The EC number for the following proteins are 5.4.2.2, phosphoglucomutase; 4.1.2.13, fructose-bisphosphate aldolase; 5.3.1.1, triosephosphate isomerase; 1.2.1.12, glyceraldehyde 3-phosphate dehydrogenase; 1.2.1.9, glyceraldehyde-3-phosphate dehydrogenase (NADP); 2.7.2.3, phosphoglycerate kinase; 5.4.2.11, phosphoglycerate mutase; 4.2.1.11, enolase; and 2.7.1.40, pyruvate kinase.

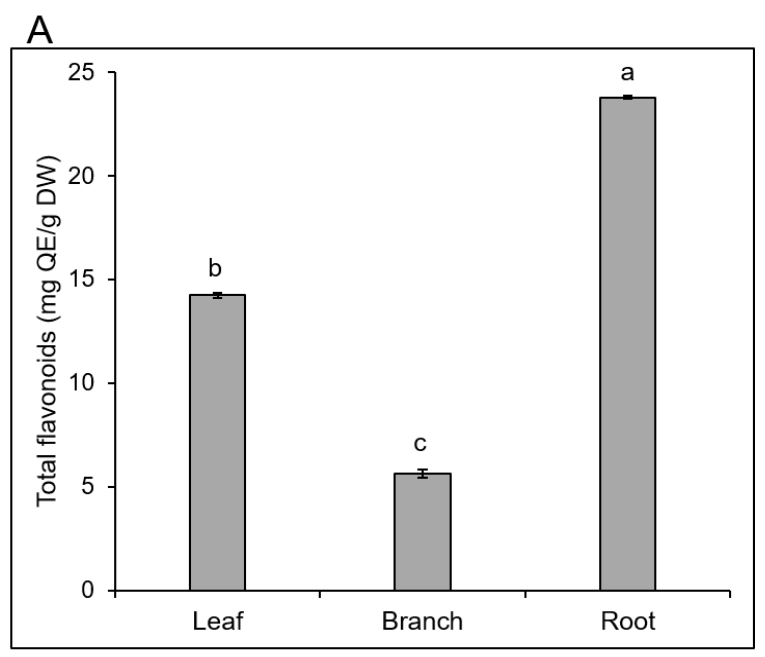

Figure 7. Cont. 
B

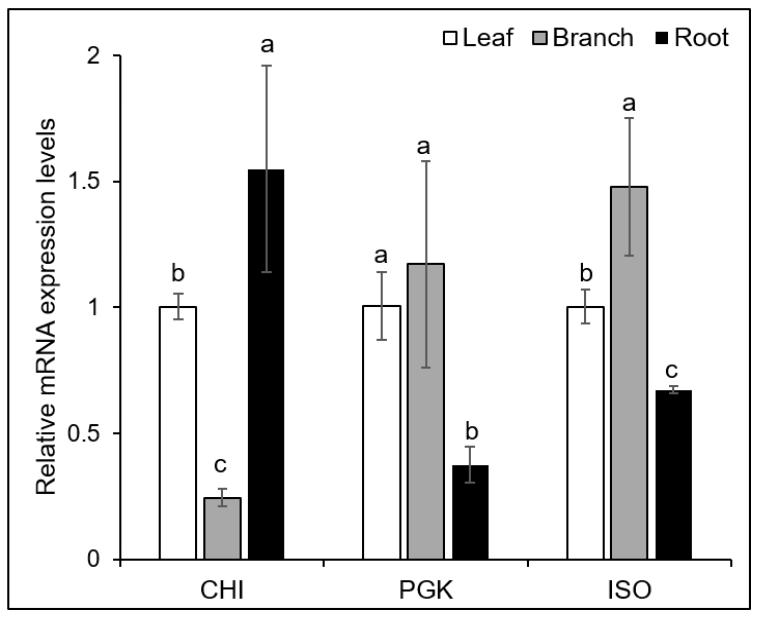

Figure 7. Total flavonoid contents and the expression of three genes in the three organs from Morus. The total flavonoids extracted from Morus leaf, branch, and root were analyzed using a colorimetric method (A). The transcript abundance of the selected genes was analyzed by qRT-PCR. Total RNA was extracted from the collected leaf, branch, and root (B). Data are shown as the means \pm SD from three independent biological replicates. Means with the same letter are not significantly different according to one-way ANOVA test $(p<0.05)$. The abbreviations are follows: QE, quercetin-3-O-rutinoside. The genes CHI, PGK, and ISO represent chalcone flavanone isomerase, phosphoglycerate kinase, and isoflavone reductase, respectively. The $\beta$-actin gene was used as a reference control gene.

\section{Discussion}

\subsection{The Secondary Metabolites and Total Flavonoid Contents are Different in Morus Leaf, Branch, and Root}

Morus is a widely distributed medicinal plant in China, and various parts of Morus are commonly used in traditional Chinese medicinal treatments [4]. To date, it has been reported that the leaf, branch, and root of Morus have various pharmacological activities, such as antidiabetic, anti-inflammatory, and anticancer [18-20]. In this study, the antioxidant activity of the root was the best among the three Morus organs examined (Figure 1B). It is known that the antioxidant-enzyme system is an important part of plant responses to oxidative stress [21]. Among the antioxidant enzymes, superoxide dismutase (SOD) and peroxidase (POD) play a key role in the antioxidant defense mechanism [22]. SOD is the first line of defense in the enzymatic pathway against free oxygen radicals [23]. POD is an enzymatic protectant that scavenges both radical and non-radical oxygen species [24]. In the present study, the abundance of peroxidase and superoxide dismutase were higher in the root than in the other organs (Table 2), which might contribute to high antioxidant activity of the Morus root.

In contrast, many secondary metabolites with various biological activities, such as alkaloids, flavonoids, polysaccharides, terpenoids, phenolic acids, stilbenoids, and coumarins, were identified in Morus [25]. Chen et al. [26] compared the chemical composition among the bark, leaf, twig, and fruit of Morus, and further analysis showed that the bark contained the highest amount of prenylated flavonoids (kuwanon $G$, sanggenon $C$, morusin, and mulberroside A) compared to the twig, leaf, and fruit. The total flavonoid contents showed a significant contribution to $\alpha$-glucosidase inhibition. In the present study, the differences among the leaf, branch, and root from Morus were uncovered at the protein level using a gel-free proteomics technique. Two proteins (chalcone flavanone isomerase and flavonoid 3,5-hydroxylase) involved in the flavonoid biosynthetic pathway were only identified in the root (Figure 4), which might mean that synthesized flavonoids accumulate in the root.

Chalcone flavanone isomerase (CHI) is a key branch-point enzyme between the phenylpropanoid and flavonoid pathways that can catalyze the synthesis of flavanones and the backbone for many downstream metabolites including flavonoids and isoflavonoids [27]. Flavonoid 3,5-hydroxylase (F3',5'Hs), which belongs to the cytochrome P450 (CYP) enzyme family [28], can catalyze the 
hydroxylation of the flavonoid B-ring at the $3^{\prime}$ and $5^{\prime}$ positions [29]. The results also indicated that dihydroxy B-ring-substituted flavonoids have a great potential to inhibit the generation of ROS and show antioxidant activity [30]. In the present study, the total flavonoid and five secondary metabolites contents were highly accumulated in the roots of Morus (Figure 1). This evidence strengthens the idea that both antioxidant enzymes and secondary metabolites in the root of Morus are responsible for the antioxidant activity.

\subsection{Anaylses of Enzymes Involved in the Glycolysis and Isoflavonoid Biosynthetic Pathway in Morus}

Glycolysis is a sequence of ten enzyme-catalyzed reactions that converts glucose into pyruvate. Proteomic analyses of leaf, branch, and root showed that proteins related to glycolysis were mostly abundant in the branch compared with the leaf and root (Figure 6). The abundance of fructose-bisphosphate aldolase (EC:4.1.2.13), phosphoglycerate kinase (EC:2.7.2.3), and enolase (EC4.2.1.11) in the branch was higher than in the leaf and root samples (Table 2). These enzymes play important roles in glycolysis. Fructose-bisphosphate aldolase catalyzes the split of fructose 1,6-bisphosphate into dihydroxyacetone phosphate and glyceraldehyde 3-phosphate [31]. Phosphoglycerate kinase catalyzes the transfer of a phosphate group from 1,3-bisphosphoglycerate to ADP via phosphoglycerate kinase, forming ATP and 3-phosphoglycerate [32]. Enolase converts 2-phosphoglycerate to phosphoenolpyruvate [33]. Cramer et al. [34] reported that the early-responding proteins to water deficit included proteins related to photosynthesis, glycolysis, translation, antioxidants, and growth, which could funnel carbon and energy into antioxidant defenses during the very early stages of plant responses to water deficit before any significant injury. The enhanced glycolysis in the mulberry branch might be engaged in a similar regulatory pathway, which enables the branch to exhibit antioxidant activity in vitro.

Furthermore, mulberry root bark is usually used in traditional Chinese medicine as a diuretic and expectorant agent, while the leaf was consumed as food by silkworms [35] and the fruit was taken as a health food [36]. However, the branch was largely neglected and ended up as fire wood material or agro-waste. Few studies have examined and confirmed the pharmacological activities of the branch bark from mulberry $[37,38]$. When comparing the abundance of commonly identified proteins from different parts of Morus, we discovered that isoflavone reductase homolog (IFRh) was most abundant in branches, approximately three times higher than in the leaf and root. Isoflavone reductase (IFR) is located in the cytoplasm and has been identified as one of the key enzymes involved in the synthesis of isoflavonoid phytoalexin [39-41]. IFR is unique to the plant kingdom and considered to have crucial roles in plant responses to various biotic and abiotic stresses. Cheng et al [42] discovered that overexpression of soybean isoflavone reductase enhanced resistance to Phytophthora sojae in soybean, though its specific biological function remains to be elucidated. The abundantly expressed isoflavone reductase homolog protein in mulberry branch inspired us to propose that intense isoflavonoid biosynthesis is present in the mulberry branch. However, the reason for this phenomenon is unknown and the function of IFRh in Morus is worth further investigation.

\section{Materials and Methods}

\subsection{Plant Materials and Growth Conditions}

Mulberry trees (Morus alba L.) were provided by the College of Agriculture and Biotechnology, Zhejiang University (Hangzhou, China). They were grown in a greenhouse under white fluorescent light $\left(160 \mu \mathrm{mol} \mathrm{m}{ }^{-2} \mathrm{~s}^{-1}, 16 \mathrm{~h}\right.$ light period/day) at $25^{\circ} \mathrm{C}$ and $70 \%$ humidity. The soil conditions were controlled to ensure normal plant growth without exposure to extreme drought or plant diseases. Leaf, branch and root were then collected, frozen in liquid nitrogen and stored at $-80^{\circ} \mathrm{C}$. For each organ, three independent experiments were performed as biological replicates. Each biological replicate means leaves, branches, and roots from three individuals were collected and analyzed by mass spectrometry separately. A total of nine plants were used in this study (Supplemental Figures S2 and S3). 


\subsection{Protein Extraction}

A portion $(0.5 \mathrm{~g})$ of each organ sample was ground into powder in liquid nitrogen using a mortar and pestle and then transferred into a polypropylene tube containing a solution of $10 \%$ trichloroacetic acid and $0.07 \% 2$-mercaptoethanol in acetone. The resulting mixture was vortexed and sonicated for $10 \mathrm{~min}$ at $4{ }^{\circ} \mathrm{C}$. The suspension was incubated for $1 \mathrm{~h}$ at $-20^{\circ} \mathrm{C}$ with vortexing every $15 \mathrm{~min}$. It was then centrifuged at $9000 \times g$ for $10 \mathrm{~min}$ at $4{ }^{\circ} \mathrm{C}$. The supernatant was discarded and the pellet was washed twice with $0.07 \% 2$-mercaptoethanol in acetone. The final pellet was dried and resuspended in lysis buffer consisting of $7 \mathrm{M}$ urea, $2 \mathrm{M}$ thiourea, $5 \% \mathrm{CHAPS}$, and $2 \mathrm{mM}$ tributylphosphine by vortexing for $1 \mathrm{~h}$ at $25^{\circ} \mathrm{C}$. The suspension was then centrifuged at 20,000 $\times \mathrm{g}$ for $20 \mathrm{~min}$ at room temperature until a clean supernatant was obtained. Protein concentrations were determined using the Bradford assay [43] with bovine serum albumin as the standard.

\subsection{Purification and Digestion of Proteins for Mass Spectrometry Analysis}

Proteins $(100 \mu \mathrm{g})$ were purified with methanol and chloroform to remove any detergent from the sample solutions [44]. Briefly, $400 \mu \mathrm{L}$ of methanol was added to each sample, and the resulting solution was mixed. Subsequently, $100 \mu \mathrm{L}$ of chloroform and $300 \mu \mathrm{L}$ of water were added to each sample, which were mixed and centrifuged at $20,000 \times g$ for $10 \mathrm{~min}$ to achieve phase separation. The upper aqueous phase was discarded and the pellets were dried. The dried pellets were resuspended in $50 \mathrm{mM} \mathrm{NH}_{4} \mathrm{HCO}_{3}$. The proteins were reduced with $50 \mathrm{mM}$ dithiothreitol for $30 \mathrm{~min}$ at $56{ }^{\circ} \mathrm{C}$ and alkylated with $50 \mathrm{mM}$ iodoacetamide for $30 \mathrm{~min}$ at $37^{\circ} \mathrm{C}$ in the dark. Alkylated proteins were digested with trypsin and lysyl endopeptidase (Wako, Osaka, Japan) at 1:100 enzyme/protein concentrations at $37^{\circ} \mathrm{C}$ for $16 \mathrm{~h}$. The resulting tryptic peptides were acidified by mixing with formic acid $(\mathrm{pH}<3)$, and the resulting solution was centrifuged at $20,000 \times g$ for $10 \mathrm{~min}$. The obtained supernatant was collected and analyzed by nanoliquid chromatography (LC)- mass spectrometry (MS).

\subsection{Nanoliquid Chromatography-Tandem Mass Spectrometry Analysis}

Peptides were analyzed using a nanospray LTQ Orbitrap mass spectrometer (Thermo Fisher Scientific, San Jose, CA, USA) with the Xcalibur software (version 2.1, Thermo Fisher Scientific, Bremen, Germany) in data-dependent acquisition mode. Using an Ultimate 3000 nanoLC system (Dionex, Germering, Germany), peptides in $0.1 \%$ formic acid were loaded onto a C18 PepMap trap column $(300 \mu \mathrm{m}$ ID $\times 5 \mathrm{~mm}$, Dionex, Sunnyvale, CA, USA) and were then eluted with a linear acetonitrile gradient $(8-30 \%$ over $150 \mathrm{~min}$ ) in $0.1 \%$ formic acid at a flow rate of $200 \mathrm{~nL} / \mathrm{min}$. The eluted peptides were separated and sprayed on a C18 capillary tip column $(75 \mu \mathrm{m}$ ID $\times 120 \mathrm{~mm}$, Nikkyo Technos, Tokyo, Japan) with a spray voltage of $1.5 \mathrm{kV}$.

Full-scan mass spectra were acquired on the LTQ Orbitrap mass spectrometer (Thermo Fisher Scientific, San Jose, CA, USA) over $400-1500 \mathrm{~m} / \mathrm{z}$ with a resolution of 30,000. A lock mass function was used for high mass accuracy [45]. The ten most intense precursor ions were selected for collision-induced fragmentation in the linear ion trap at a normalized collision energy of $35 \%$. Dynamic exclusion was employed within $90 \mathrm{~s}$ to prevent the repetitive selection of peptides [46].

\subsection{Protein Identification from the Mass Spectrometry Data}

Proteins were identified using the Mascot search engine (version 2.5.1; Matrix Science, London, UK) with the Morus Genome database (MorusDB) (version 2.0, https:/ / morus.swu.edu.cn/morusdb / datasets). The acquired raw data files were processed using Proteome Discoverer (version 1.4.0.288, Thermo Fisher Scientific, Bremen, Germany). The parameters used in Mascot searches were as follows: carbamidomethylation of cysteine was set as a fixed modification and oxidation of methionine was set as a variable modification. Trypsin was specified as the proteolytic enzyme, and one missed cleavage was allowed. The peptide mass tolerance was set at $10 \mathrm{ppm}$, the fragment mass tolerance was set at $0.8 \mathrm{Da}$, and the peptide charge was set at $+2,+3$, and +4 . An automatic decoy database 
search was performed as part of the search. Mascot results were filtered with Mascot Percolator to improve the accuracy and sensitivity of peptide identification [47]. The false discovery rates for peptide identification in all searches were less than $1.0 \%$. Peptides with a percolator ion score of more than $13(p<0.05)$ were used for protein identification. Protein abundance was analyzed based on the exponentially modified protein abundance index (emPAI) value [48]. Mascot-derived emPAI values were converted to molar percentages by normalizing against the sum of all emPAI values for the acquisition. Briefly, the mean of three emPAI values was divided by the sum of the emPAI values for all identified proteins and multiplied by 100 . The protein content was estimated by the molar fraction percentage $(\mathrm{mol} \%)$.

\subsection{Functional Analysis of Identified Proteins}

Protein functions were categorized using MapMan bin codes as previously described [49]. The small-scale prediction of the identified proteins from Mahonia was performed by transferring annotations from the Arabidopsis thaliana genome and considering orthologous genes. Pathway mapping of identified proteins was performed using the Kyoto Encyclopedia of Genes and Genomes (KEGG) database (https:/ / www.kegg.jp/) [50].

\subsection{Quantitative Analysis of Metabolites from Morus}

A portion ( $0.2 \mathrm{~g}$ dry weight) of collected organ sample was sonicated in $150 \mathrm{~mL}$ of methanol for $2 \mathrm{~h}$, centrifuged at $10,000 \times g$ for $10 \mathrm{~min}$, and the supernatant was collected. The methanol extracts were dried in a rotary evaporator at $50{ }^{\circ} \mathrm{C}$. For root samples, the obtained residue was dissolved in $10 \mathrm{~mL}$ of methanol. For branch and leaf samples, the obtained residue was dissolved in $2 \mathrm{~mL}$ of methanol. The dissolved samples were then filtered through a $0.45-\mu \mathrm{m}$ filter (Millipore, Bullerica, MA, USA) for HPLC analysis. Several standard compounds, which consisted of mulberroside A, oxyresveratrol, kuwanone $\mathrm{H}$, chalcomoracin, and morusin, were provided by Zhejiang Institute for Food and Drug Control (Hangzhou, China). For quantification, a calibration curve was constructed using the standard solutions diluted in methanol at six different concentrations: mulberroside $\mathrm{A}(0.05,0.1,0.25,0.375,0.5$, and $\left.0.75 \mathrm{mg} \mathrm{mL}^{-1}\right)$, oxyresveratrol $\left(0.001,0.005,0.01,0.025,0.05\right.$, and $\left.0.1 \mathrm{mg} \mathrm{mL}^{-1}\right)$, kuwanone $\mathrm{H}(0.01$, $0.05,0.1,0.2,0.3$, and $\left.0.5 \mathrm{mg} \mathrm{mL}^{-1}\right)$, chalcomoracin $\left(2.36,4.72,9.44,14.16,18.88\right.$, and $\left.23.6 \mathrm{mg} \mathrm{mL}^{-1}\right)$, and morusin $\left(0.01,0.05,0.1,0.25,0.5\right.$, and $\left.1 \mathrm{mg} \mathrm{mL}^{-1}\right)$. For HPLC analysis, $10 \mu \mathrm{L}$ of the standard solutions and samples were used.

HPLC analysis was performed on a Waters 2695 Alliance HPLC system (Waters, Milford, MA, USA) equipped with a photodiode array detector, an online degasser and an auto-sampler for solvent delivery. Compounds in samples were separated using reverse-phase HPLC. A C18 column $(4.6 \mathrm{~mm}$ ID $\times 250 \mathrm{~mm}$, Agilent, Santa Clara, CA, USA) was used with a flow rate of $1 \mathrm{~mL} \mathrm{~min}^{-1}$ at $40{ }^{\circ} \mathrm{C}$. The solvent system consisted of a linear gradient from $10 \%$ to $95 \%(v / v)$ acetonitrile in water with $0.1 \%$ phosphoric acid over a period of $70 \mathrm{~min}$ followed by an isocratic elution with $95 \%$ for $5 \mathrm{~min}$. The spectra were measured at $320 \mathrm{~nm}$ and the retention time and ultraviolet spectra of the samples' peaks were compared with that of the standards' peaks.

\subsection{In Vitro Antioxidant Activity Analysis of Mulberry Leaf, Branch, and Root}

For the determination of the antioxidant activities of mulberry leaf, branch and root, $\mathrm{ABTS}^{+}$ scavenging activity, hydroxyl free radical and $\mathrm{O}_{2}{ }^{-}$scavenging activity were analyses. The $\mathrm{ABTS}^{+}$ scavenging activities within different organs were determined using a total antioxidant capacity assay kit (A015-2, Nanjing Jiancheng Bioengineering Institute, Nanjing, China) following the manufacturer's protocol. Briefly, $10 \mu \mathrm{L}$ of each sample were mixed with diluted $\mathrm{ABTS}^{+}$solution and then shaken vigorously for $6 \mathrm{~min}$ at room temperature in the dark. The absorbance of the samples was measured at $405 \mathrm{~nm}$ immediately after incubation. A calibration curve was constructed using absorbance values measured when $\mathrm{ABTS}^{+}$solution was mixed with a standard antioxidant-Trolox at $0.1 \mathrm{mM}$, 
$0.2 \mathrm{mM}, 0.4 \mathrm{mM}, 0.8 \mathrm{mM}$ and $1.0 \mathrm{mM}$. The antioxidant activity of each group was measured as a Trolox-Equivalent Antioxidant Capacity (TEAC).

The hydroxyl free radical assay was performed using kit A018 purchased from the Nanjing Jiancheng Bioengineering Institute following the manufacturer's protocol based on the principle of the Fenton reaction [51]. Samples were mixed with reaction buffer and reacted at $37^{\circ} \mathrm{C}$ for $1 \mathrm{~min}$ and terminated with the addition of developer. The absorbance of the samples was measured at $550 \mathrm{~nm}$ after developing for $20 \mathrm{~min}$; the standard sample contained $0.03 \% \mathrm{H}_{2} \mathrm{O}_{2}$ as a control.

The $\mathrm{O}_{2}{ }^{-}$scavenging activities were determined using the inhibition and produce superoxide anion assay kit (A052, Nanjing Jiancheng Bioengineering Institute, Nanjing, China) according to manufacturer's protocol. Samples were mixed with reaction buffer, incubated at $37^{\circ} \mathrm{C}$ for $40 \mathrm{~min}$ and terminated by the addition of developer. The absorbance of the samples was measured at $550 \mathrm{~nm}$ after developing for $10 \mathrm{~min}$ developing; a vitamin $C$ standard solution at $0.15 \mathrm{mg} \mathrm{mL}^{-1}$ was used as the control.

\subsection{RNA Extraction and Quantitative Reverse Transcription-Polymerase Chain Reaction Analysis}

Samples ( $0.1 \mathrm{~g}$ fresh weight) were ground to powder in liquid nitrogen using a sterilized mortar and pestle. Total RNA was extracted using a Quick RNA Isolation Kit (Huayueyang Biotechnology, Beijing, China) and reverse-transcribed using a 5X All-In-One RT MasterMix with AccuRT Genomic DNA Removal Kit (Applied Biological Materials Ins, CA) according to manufacturers' protocols. The primers were designed using Primer Premier 6.0. qRT-PCR was performed in a $10 \mu \mathrm{L}$ reaction volume using an Evagreen $2 \times$ qPCR MasterMix (Applied Biological Materials Ins, CA) in an IQ5 multicolor real-time PCR detection System (Bio-Rad, Hercules, CA, USA). The relative quantification method $(2-\Delta \Delta C T)$ was used to evaluate the quantitative variation between treatments. $\beta$-actin (GeneBank ID: HQ 163776) served as an internal control to normalize target gene quantities [52]. The gene-specific primers are listed in Supplemental Table S5. The qRT-PCR results were analyzed using the Statistical Product and Service Solutions software (version 20.0, IBM, Armonk, NY, USA).

\subsection{Quantitative Analysis of the Total Flavonoids in Three Morus Organs}

The total flavonoid contents of the three organs in Morus was determined by a colorimetric method as described previously with minor modifications [53]. Briefly, a portion $(2.0 \mathrm{~g})$ of each freeze-dried organ sample was sonicated in $100 \mathrm{~mL}$ of methanol for $30 \mathrm{~min}$, centrifuged at $8000 \times g$ for $10 \mathrm{~min}$, and the supernatant was collected. The pellet was resuspended in $100 \mathrm{~mL}$ of methanol and the resulting suspension was sonicated for $30 \mathrm{~min}$. The methanol extracts were dried in a rotary evaporator at $50{ }^{\circ} \mathrm{C}$. The obtained residue was dissolved in methanol using $10 \mathrm{~mL}$ in a volumetric flask and brought to volume by methanol. One milliliter of the final extract was placed in a $10 \mathrm{~mL}$ volumetric flask. Then, $0.5 \mathrm{~mL}$ of $5 \% \mathrm{NaNO}_{2}$ was added and the mixture was maintained for $5 \mathrm{~min}$ at room temperature. After incubation, $0.5 \mathrm{~mL}$ of $10 \% \mathrm{Al}\left(\mathrm{NO}_{3}\right)_{3}$ was added to the reaction mixture and incubated for $5 \mathrm{~min}$. Next, $1.5 \mathrm{~mL}$ of $2 \mathrm{M} \mathrm{NaOH}$ was added and methanol was added up to volume. After incubating for $15 \mathrm{~min}$, the absorbance was measured at $510 \mathrm{~nm}$. The data are expressed as $\mathrm{mg}$ quercetin-3-O-rutinoside (rutin) equivalents (QE)/g dry weight (DW), as quercetin-3-O-rutinoside was used as a reference standard for the quantification of the total flavonoids.

\subsection{Statistical Analysis}

The SPSS statistical software (version 22.0, IBM, Armonk, NY, USA) was used for the statistical evaluation of the results. Statistical significance was evaluated by Student's t-test when only two groups were compared and with one-way ANOVA test when multiple groups were compared. All results are presented as the mean \pm SD from three independent biological replicates. A $p$-value less than 0.05 was considered statistically significant. 


\section{Conclusions}

Morus is a medicinal plant with various biological activities. In this study, it is indicated that the five secondary metabolites, including mulberroside $\mathrm{A}$, oxyresveratrol, kuwanone $\mathrm{H}$, chalcomoracin, and morusin, and total flavonoids contents in Morus roots are higher than in other organs, which might be responsible for its highest antioxidant activity. Proteomic analysis of the leaf, branch, and root from Morus revealed that proteins related to the flavonoid pathway such as chalcone flavanone isomerase and flavonoid 3,5-hydroxylase were accumulated in the root, resulting in the highest total flavonoid contents among the three examined organs. Additionally, the protein expression profiling of the leaf, branch, and root in Morus will enrich the proteome database of Morus. Additionally, the present findings suggest that flavonoid biosynthesis is an important function in Morus root.

Supplementary Materials: Supplementary Materials can be found at http:/ / www.mdpi.com/1422-0067/20/ 2/365/s1. Supplemental Figure S1. Comparison of organ-specific proteins related to secondary metabolism. Supplemental Figure S2. Experimental design of the proteomic study. Supplemental Figure S3. Workflow of the gel-free/label-free proteomic methods in the present study. Supplemental Figure S4. Pie chart of functional categorization of leaf, branch, and root in Morus. Supplemental Table S1. Proteins Identified in the leaf of Morus by gel-free/label-free proteomic analysis. Supplemental Table S2. Proteins Identified in the branch of Morus by gel-free/label-free proteomic analysis. Supplemental Table S3. Proteins Identified in the root of Morus by gel-free/label-free proteomic analysis. Supplemental Table S4. Contents of total flavonoids in different organs of Morus. Supplemental Table S5. Primers of three genes used in this study.

Author Contributions: Conceptualization: J.T.; methodology: W.Z. and S.K.; software: S.L. and B.Y.; validation: Z.Z.; formal analysis: W.Z.; investigation: W.Z.; resources: B.Y.; data curation: Z.G.; writing-original draft preparation: W.Z. and Z.Z.; writing-review and editing: W.Z., Z.Z., J.T., and S.K.; visualization: S.L.; supervision: J.T.; project administration: W.Z.; funding acquisition: W.Z. and J.T.

Funding: This research was funded by the National Natural Science Foundation of China, grant numbers 81872973 and 81603078, and the Zhejiang Provincial Science and Technology Planning Project, grant number $2016 \mathrm{C} 04005$.

Acknowledgments: We thank Xiaojian Yin at the National Institute of Crop Science (Japan) for experimental support during this research.

Conflicts of Interest: The authors declare no conflict of interest.

\section{Abbreviations}

$\begin{array}{ll}\text { ABTS } & \text { 2,2'-Azino-bis (3-ethylbenzothiazoline-6-sulfonic acid) } \\ \text { CHAPS } & \text { 3-[(3-Cholamidopropyl) dimethylammonio] propanesulfonate } \\ \text { CHI } & \text { Chalcone flavanone isomerase } \\ \text { emPAI } & \text { Exponentially-modified protein abundance index } \\ \text { HPLC } & \text { High-performance liquid chromatography } \\ \text { ISO } & \text { Isoflavone reductase } \\ \text { IFRh } & \text { Isoflavonoid reductase homolog } \\ \text { MS } & \text { Mass spectrometry } \\ \text { MVA } & \text { Mevalonate } \\ \text { PGK } & \text { Phosphoglycerate kinase } \\ \text { POD } & \text { Peroxidase } \\ \text { qRT-PCR } & \text { Quantitative reverse transcription-polymerase chain reaction } \\ \text { SOD } & \text { Superoxide dismutase } \\ \text { TCA } & \text { Tricarboxylic acid } \\ \text { TEAC } & \text { Trolox-equivalent antioxidant capacity }\end{array}$

\section{References}

1. Umate, P. Mulberry improvements via plastid transformation and tissue culture engineering. Plant Signal. Behav. 2010, 5, 785-787. [CrossRef] [PubMed]

2. Qin, J.; He, N.J.; Huang, X.Z.; Xiang, Z.H. Development of mulberry ecological industry and sericulture. Sci. Seric. 2010, 36, 984-989. (In Chinese) 
3. Liu, Y.; Willison, J.H.M. Prospects for cultivating white mulberry (Morus alba) in the drawdown zone of the Three Gorges Reservoir, China. Environ. Sci. Pollut. Res. 2013, 20, 7142-7151. [CrossRef] [PubMed]

4. Sun, S.G.; Chen, R.Y.; Yu, D.Q. Structures of two new benzofuran derivatives from the bark of mulberry tree (Morus macroura Miq.). J. Asian Nat. Prod. Res. 2001, 3, 253-259. [CrossRef] [PubMed]

5. Carrizzo, A.; Ambrosio, M.; Damato, A.; Madonna, M.; Storto, M.; Capocci, L.; Campiglia, P.; Sommella, E.; Trimarco, V.; Rozza, F.; et al. Morus alba extract modulates blood pressure homeostasis through eNOS signaling. Mol. Nutr. Food Res. 2016, 60, 1-8. [CrossRef] [PubMed]

6. Yuan, Q.; Xie, Y.; Wang, W.; Yan, Y.; Ye, H.; Jabbar, S.; Zeng, X. Extraction iptimization, characterization and antioxidant activity in vitro of polysaccharides from mulberry (Morus alba L.) leaves. Carbohyd. Polym. 2015, 128, 52-62. [CrossRef] [PubMed]

7. Liu, H.Y.; Wang, J.; Ma, J.; Zhang, Y.Q. Interference effect of oral administration of mulberry branch bark powder on the incidence of type II diabetes in mice induced by streptozotocin. Food Nutr. Res. 2016, 60, 31606. [CrossRef] [PubMed]

8. Qi, S.Z.; Tuo, Z.D.; Li, J.L.; Xing, S.S.; Li, B.B.; Zhang, L.; Lee, H.S.; Chen, J.G.; Cui, L. Effects of Morus root bark extract and active constituents on blood lipids in hyperlipidemia rats. J. Ethnopharmacol. 2016, 180, 54-59. [CrossRef]

9. Shang, X.F.; He, X.R.; He, X.Y.; Li, M.X.; Zhang, R.X.; Fan, P.C.; Zhang, Q.L.; Jia, Z.P. The genus Scutellaria an ethnopharmacological and phytochemical review. J. Ethnopharmacol. 2010, 128, 279-313. [CrossRef] [PubMed]

10. Lam, S.C.; Liu, X.; Chen, X.Q.; Hu, D.J.; Zhao, J.; Long, Z.R.; Fan, B.; Li, S.P. Chemical characteristics of different parts of Coreopsis tinctorial in China using microwave-assisted extraction and high-performance liquid chromatography followed by chemometric analysis. J. Sep. Sci. 2016, 39, 2919-2927. [CrossRef] [PubMed]

11. Khan, M.A.; Rahman, A.A.; Islam, S.; Khandokhar, P.; Parvin, S.; Islam, M.B.; Hossain, M.; Rashid, M.; Sadik, G.; Nasrin, S.; Mollah, M.N.H.; Alam, A.H.M.K. A comparative study on the antioxidant activity of methanolic extracts from different parts of Morus alba L. (Moraceae). BMC Research Notes 2013, 6, 24. [CrossRef] [PubMed]

12. Wang, W.; Zu, Y.; Fu, Y.; Efferth, T. In vitro antioxidant and antimicrobial activity of extracts from Morus alba L. leaves, stems and fruits. Am. J. Chin. Med. 2012, 40,349-356. [CrossRef]

13. Chang, L.W.; Juang, L.J.; Wang, B.S.; Wang, M.Y.; Tai, H.M.; Hung, W.J.; Chen, Y.J.; Huang, M.H. Antioxidant and antityrosinase activity of mulberry (Morus alba L.) twigs and root bark. Food Chem. Toxicol. 2011, 49, 785-790. [CrossRef] [PubMed]

14. Zhang, S.; Zhang, L.; Tai, Y.; Wang, X.; Ho, C.T.; Wan, X. Gene discovery of characteristic metabolic pathways in the tea plant (Camellia sinensis) using 'Omics'-based network approaches: A future perspective. Front. Plant Sci. 2018, 9, 480. [CrossRef] [PubMed]

15. García-Sevillano, M.A.; García-Barrera, T.; Abril, N.; Pueyo, C.; Lopez-Barea, J.; Gomez-Ariza, J.L. Omics technologies and their applications to evaluate metal toxicity in mice M. spretus as a bioindicator. J. Proteom. 2014, 104, 4-23. [CrossRef]

16. Zhu, W.; Hu, J.; Wang, X.; Tian, J.K.; Komatsu, S. Organ-specific analysis of Mahonia using gel-free/label-free proteomic technique. J. Proteome Res. 2015, 14, 2669-2685. [CrossRef] [PubMed]

17. Ji, X.L.; Gai, Y.P.; Zheng, C.C.; Mu, Z.M. Comparative proteomic analysis provides new insights into mulberry dwarf responses in mulberry (Morus alba L.). Proteomics 2009, 9, 5328-5339. [CrossRef]

18. Ma, X.; Iwanaka, N.; Masuda, S.; Karaike, K.; Egawa, T.; Hamada, T.; Toyoda, T.; Myamoto, L.; Nakao, K.; Hayashi, T. Morus alba leaf extract stimulates 5'-AMP-activated protein kinase in isolated rat skeletal muscle. J. Ethnopharmacol. 2009, 122, 54-59. [CrossRef] [PubMed]

19. Jung, J.W.; Ko, W.M.; Park, J.H.; Seo, K.H.; Oh, E.J.; Lee, D.Y.; Lee, D.S.; Kim, Y.C.; Lim, D.W.; Han, D.; Baek, N.I. Isoprenylated flavonoids from the root bark of Morus alba and their hepatoprptective and neuroprotective activities. Arch. Pharm. Res. 2015, 38, 2066-2075. [CrossRef]

20. Eo, H.J.; Park, G.H.; Jeong, J.B. The involvement of cyclin D1 degradation through GSK3 $\beta$-mediated threonine-286 phosphorylation-dependent nuclear export in anti-cancer activity of mulberry root bark extracts. Phytomedicine 2016, 23, 105-113. [CrossRef] 
21. Chahid, K.; Laglaoui, A.; Zantar, S.; Ennabili, A. Antioxidant-enzyme reaction to the oxidative stress due to alpha-cypermethrin, chlorpyriphos, and pirimicarb in tomato (Lycopersicon esculentum Mill.). Environ. Sci. Pollut. Res. Int. 2015, 22, 18115-18126. [CrossRef] [PubMed]

22. Qin, R.; Jiao, Y.; Zhang, S.; Jiang, W.; Liu, D. Effects of aluminum on nucleoli in root tip cells and selected physiological and biochemical characters in Allium cepa var. agrogarum L. BMC Plant Biol. 2010, 10, 225.

23. Prashanth, S.R.; Sadhasivam, V.; Parida, A. Over expression of cytosolic copper/zine superoxide dismutase from a mangrove plant Avicennia marina in indica rice var: Pusa basmati-1 confers abiotic stress tolerance. Transgenic Res. 2008, 17, 281-291. [CrossRef] [PubMed]

24. Gill, S.S.; Tuteja, N. Reactive oxygen species and antioxidant machinery in abiotic stress tolerance in crop plants. Plant Physiol. Biochem. 2010, 48, 909-930. [CrossRef] [PubMed]

25. Chan, E.W.C.; Lye, P.Y.; Wang, S.K. Phytochemistry, pharmacology, and clinical trials of Morus alba. Chin. J. Nat. Med. 2016, 14, 17-30. [PubMed]

26. Chen, Z.Y.; Du, X.; Yang, Y.Y.; Cui, X.M.; Zhang, Z.J.; Li, Y. Comparative study of chemical composition and active components against $\alpha$-glucosidase of various medicinal parts of Morus alba L. Biomed. Chromatogr. 2018, 32, e4328. [CrossRef] [PubMed]

27. Dastmalchi, M.; Dhaubhadel, S. Soybean chalcone isomerase: Evolution of the fold, and the differential expression and localization of the gene family. Planta 2015, 241, 507-523. [CrossRef]

28. Bogs, J.; Ebadi, A.; McDavid, D.; Robinson, S.P. Identification of the flavonoid hydroxylases from grapevine and their regulation during fruit development. Plant Physiol. 2006, 140, 279-291. [CrossRef]

29. Liu, S.H.; Ju, J.F.; Xia, G.M. Identification of the flavonoid 3'-hydroxylase and flavonoid 3',5'-hydroxylase genes from Antarctic moss and their regulation during abiotic stress. Gene 2014, 543, 145-152. [CrossRef]

30. Fini, A.; Brunetti, C.; Ferdinando, M.D.; Ferrini, F.; Tattini, M. Stress-induced flavonoid biosynthesis and the antioxidant machinery of plants. Plant Signal. Behav. 2011, 5, 709-711. [CrossRef]

31. Zgiby, S.M.; Thomson, G.J.; Qamar, S.; Berry, A. Exploring substrate binding and discrimination in fructose 1,6-bisphosphate and tagatose 1,6-bisphosphate aldolases. Eur. J. Biochem. 2000, 267, 1858-1868. [CrossRef] [PubMed]

32. Watson, H.C.; Walker, N.P.; Shaw, P.J.; Bryant, T.N.; Wendell, P.L.; Fothergill, L.A.; Perkins, R.E.; Conroy, S.C.; Dobson, M.J.; Tuite, M.F. Sequence and structure of yeast phosphoglycerate kinase. EMBO J. 1982, 1, 1635-1640. [CrossRef] [PubMed]

33. Hoom, R.K.; Flickweert, J.P.; Staal, G.E. Purification and properties of enolase of human erythroctyes. Int. J. Biochem. 1974, 5, 845-852.

34. Cramer, G.R.; Sluyter, S.C.V.; Hopper, D.W.; Pascovici, D.; Keighley, T.; Haynes, P.A. Proteomic analysis indicates massive changes in metabolism prior to the inhibition of growth and photosynthesis of grapevine (Vitis vinifera L.) in response to water deficit. BMC Plant Biol. 2013, 13, 49. [CrossRef] [PubMed]

35. Wang, D.; Dong, Z.; Zhang, Y.; Guo, K.; Guo, P.; Zhao, P.; Xia, Q. Proteomics provides insight into the interaction between mulberry and silkworm. J. Proteome Res. 2017, 16, 2477-2480. [CrossRef] [PubMed]

36. Zhang, H.; Ma, Z.F.; Luo, X.; Li, X. Effects of mulberry fruit (Morus alba L.) consumption on health outcomes: A mini-review. Antioxidants 2018, 7, 69. [CrossRef]

37. Qiu, F.; He, T.Z.; Zhang, Y.Q. The isolation and the characterization of two polysaccharides from the branch bark of mulberry (Morus alba L.). Arch. Pharm. Res. 2016, 39, 887-896. [CrossRef]

38. Wang, S.; Fang, M.; Ma, Y.L.; Zhang, Y.Q. Preparation of the branch bark ethanol extract in mulberry Morus alba, its antioxidation, and antihyperglycemic activity in vivo. Evid.-Based Complement. Altern. 2014, 2014, 569652.

39. Graham, T.L.; Kim, J.E.; Graham, M.Y. Role of constitutive isoflavone conjugates in the accumulation of glyceollin in soybean infected with Phytophthora megasperma. Mol. Plant Microbe Interact. 1990, 3, 157-166. [CrossRef]

40. Guo, L.; Dixon, R.A.; Paiva, N.L. Conversion of vestitone to medicarpin in Alfalfa (Medicago sativa L.) is catalyzed by two independent enzymes. J. Biol. Chem. 1994, 269, 22372-22378.

41. Cooper, J.D.; Qiu, F.; Paiva, N.L. Biotransformation of an exogenously supplied isoflavonoid by transgenic tobacco cells expressing alfalfa isoflavone reductase. Plant Cell Rep. 2002, 20, 876-884.

42. Cheng, Q.; Li, N.; Dong, L.; Zhang, D.; Fang, S.; Jiang, L.; Wang, X.; Xu, P.; Zhang, S. Overexpression of soybean isoflavone reductase (GmIFR) enhances resistance to Phytophthora sojae in soybean. Front. Plant. Sci. 2015, 6, 1024. [CrossRef] [PubMed] 
43. Bradford, M.M. A rapid and sensitive method for the quantitation of microgram quantities of protein utilizing the principle of proteindye binding. Anal. Biochem. 1976, 72, 248-254. [CrossRef]

44. Nanjo, Y.; Skultety, L.; Uvackova, L.; Klubicova, K.; Hajduch, M.; Komatsu, S. Mass spectrometry-based analysis of proteomic changes in the root tips of flooded soybean seedlings. J. Proteome Res. 2012, 11, 372-385. [CrossRef] [PubMed]

45. Olsen, J.V.; de Godoy, L.M.F.; Li, G.Q.; Macek, B.; Mortensen, P.; Pesch, R.; Makarov, A.; Lange, O.; Horning, S.; Mann, M. Parts per million mass accuracy on an Orbitrap mass spectrometer via lock mass injection into a C-trap. Mol. Cell. Proteom. 2005, 4, 2010-2021. [CrossRef] [PubMed]

46. Zhang, Y.; Wen, Z.H.; Washburn, M.P.; Florens, L. Effect of dynamic exclusion duration on spectral count based quantitative proteomics. Anal. Chem. 2009, 81, 6317-6326. [CrossRef] [PubMed]

47. Brosch, M.; Yu, L.; Hubbard, T.; Choudhary, J. Accurate and sensitive peptide identification with MASCOT percolator. J. Proteome Res. 2009, 8, 3176-3181. [CrossRef] [PubMed]

48. Shinoda, K.; Tomita, M.; Ishihama, Y. emPAI Calc-for the estimation of protein abundance from large-scale identification data by liquid chromatography-tandem mass spectrometry. Bioinfomatics 2010, 26, 576-577. [CrossRef] [PubMed]

49. Usadel, B.; Nagel, A.; Thimm, O.; Redestig, H.; Blaesing, O.E.; Natalia, P.R.; Selbig, J.; Hannemann, J.; Piques, M.C.; Steinhauser, D.; et al. Extension of the visualization tool MapMan to allow statistical analysis of arrays, display of corresponding genes, and comparison with known responses. Plant Physiol. 2005, 138, 1195-1204. [CrossRef]

50. Kanehisa, M.; Goto, S. KEGG: Kyoto encyclopedia of genes and genomes. Nucleic Acids Res. 2000, $28,27-30$. [CrossRef]

51. Fenton, H.J.H. Oxidation of tartaric acid in presence of iron. J. Chem. Soc. Trans. 1894, 65, 899-910. [CrossRef]

52. Guan, Q.J.; Yu, J.J.; Zhu, W.; Yang, B.X.; Li, Y.H.; Zhang, L.; Tian, J.K. RNA-Seq transcriptome analysis of the Morus alba L. leaves exposed to high-level UV-B with and without dark treatment. Gene 2018, 645, 60-68. [CrossRef] [PubMed]

53. Chen, W.; Li, Y.; Bao, T.; Gowd, V. Mulberry fruit extract affords protection against ethyl carbamate-induced cytotoxicity and oxidative stress. Oxid. Med. Cell. Longev. 2017, 2017, 1594963. [CrossRef] [PubMed]

(C) 2019 by the authors. Licensee MDPI, Basel, Switzerland. This article is an open access article distributed under the terms and conditions of the Creative Commons Attribution (CC BY) license (http:/ / creativecommons.org/licenses/by/4.0/). 